Research Article

\title{
Stress Response and Damage Characteristics of Local Members of a Structure due to Tunnel Blasting Vibrations Based on the High-Order Local Modal Analysis
}

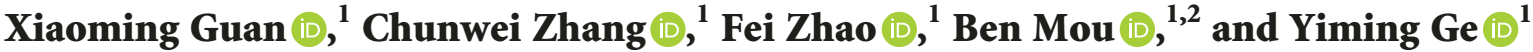 \\ ${ }^{1}$ School of Civil Engineering, Qingdao University of Technology, Qingdao 266033, China \\ ${ }^{2}$ Cooperative Innovation Center of Engineering Construction and Safety in Shandong Blue Economic Zone, \\ Qingdao University of Technology, Qingdao 266033, China
}

Correspondence should be addressed to Chunwei Zhang; zhangchunwei@qut.edu.cn

Received 18 October 2018; Revised 21 March 2019; Accepted 7 May 2019; Published 27 June 2019

Academic Editor: Rafał Burdzik

Copyright (c) 2019 Xiaoming Guan et al. This is an open access article distributed under the Creative Commons Attribution License, which permits unrestricted use, distribution, and reproduction in any medium, provided the original work is properly cited.

\begin{abstract}
Damage characteristics and dynamic stress response of aging masonry structures for blast-induced ground motion were performed using high-order local modal analysis method. A complete investigation of damage types and locations of aging masonry buildings due to tunnel blasting vibration were performed by on-site survey. A typical 2-storey aging masonry building located above a tunnel was selected for dynamic response analysis. The experimental dynamic characteristics of the structure were determined by using the operational modal analysis (OMA) method. Finite element models for the masonry structures were updated by modifying material parameters based on OMA results. The first five natural frequencies of the updated finite element models ranged from $8.80-24.99 \mathrm{~Hz}$, and the first five modes were global modes. The sixth to twentieth natural frequencies ranged from $26.10-36.34 \mathrm{~Hz}$, and the sixth to twentieth modes were local modes whose deformation was greater than the global deformation. Since the principal frequencies of the tunnel blast vibration were mostly higher than the natural global modes' frequencies and were much closer to the natural frequencies of local members, local members experienced more intensive vibrations compared to the main body structure. The principal compressive stress (PCS) and principal tensile stress (PTS) of local members were several times greater than that of the main body structure. Therefore, local members of the masonry building suffered most from the tunnel blasting vibration. Corners due to stress concentration, the contact area between brick and concrete, local members, and precast floor seams are prone to damage during tunnel blasting. With the vibration velocity increasing, the PCS and PTS of local members gradually increase. But, the PTS ratio of local members decreases with the increase of peak particle velocities. The dynamic response analysis result and the damage locations using high-order local modal analysis method are in accordance with the damage found at the site.
\end{abstract}

\section{Introduction}

Nowadays, with the remarkable progress of railways, highways, and subways, there is an increasing number of shallow buried tunnels being built beneath buildings in old urban districts. Damage to aging buildings due to weakened seismic capacity is common during tunnel drilling and blasting. Frequent vibration induced by tunnel blasting further exacerbates damage to the building and may cause serious failure of the building. Multiple damage analyses of buildings near tunnel blasting projects were conducted.
Results showed that some local non-load-bearing members of structures such as corners of stress concentration, brick and concrete contact areas, precast floor seams, and infilled walls experienced cracking. However, cracking in loadbearing components, such as beams, slabs, columns, and shear walls, was not found. High-frequency tunnel blasting induced damage characteristics are clearly different from damage induced by natural seismic ground motion.

Recently, much effort has been spent on estimating the dynamic response and damage to frame and masonry structures relative to blasting-induced ground motion. The 
structural damage of a typical low-to high-rise RC frames is performed using a shaking table on a $1: 5$-scale frame model. Conventional damage assessment methods adopted in seismic analysis are not applicable for high-frequency ground motion [1]. Distributed concrete damage in a two-storey frame structure induced by high-frequency ground motion is simulated using a fracture indicator determined by the equivalent tensile strain [2]. Structures do not primarily respond in their global structural modes under high-frequency ground motion [3]. The damage pattern is closely associated with structural high-vibration modes. The high-frequency ground motion damage may be characterized by widespread concrete damage over the structural members in the lowest few storeys [4]. Considering the effects of ground motion spatial variations and soil-structure interactions, both the low structural vibration modes and the first elemental vibration mode may govern the dynamic structural response depending on ground motion frequency and structural response parameters [5]. With regards to multistorey masonry structures, the most severe damage occurs in two-storey structures while a six-storey RC frame composed of masonry walls experiences less damage. The damage to ground motion relationship is governed by the force-stress relationship rather than the ductility [6].

Safety assessments of structures subjected to near-field blast-induced ground excitations were firstly performed using OMA. A reinforced concrete building, a masonry building, a reinforced concrete highway bridge, and a masonry arch bridge were selected for safety evaluation. The OMA method can determine experimental dynamic characteristics of structures under near-field blast-induced ground excitations [7, 8]. For the large structure, such as buildings and bridges, low-order global structural modes are not sensitive to local damage. Therefore, analyzing the frequency and vibration of global modes to explore structural damage is greatly limited. However, high-order modes are sensitive to local structural damage $[9,10]$. Deformation of local members under high-order modes is much larger than other components. High-order modes can strongly reflect the local damage of the structure. Therefore, by exploring high-order local structural modes, local members with large vibration potential in the structure can be identified, which provides researchers a clear target in the search for the vibration and damage characteristics of existing structural members.

The method of indirect vibration monitoring and safety control standard of the deep underground pipeline was proposed [11]. The stress response of the structure to vibrations induced by only $Z$ direction tunnel blasting were studied using modal analysis method, but the response of the structure caused by multidirection vibrations had not been studied [12]. Although the stress response of the structure to vibrations during tunnel blasting was studied based on the modal analysis method, the OMA test, and model updating of the structure, modal analyses of local members of the building and interaction between external blast vibration frequency and structural modes had not been investigated in the paper [13]. Based on the building modal analysis, the blasting vibration control tests were carried out using nonelectric detonators and digital electronic detonators, respectively. The results showed that digital electronic detonators with each hole interval detonation could reduce the peak vibration velocity much more than nonelectric detonators [14]. The displacement response of the masonry under different peak particle velocities was mainly investigated. The interstorey displacement angle ratio is not suited to evaluate the buildings safety under tunnel blasting [15]. According to the first four modal parameters obtained from the operational modal analysis (OMA) and based on the structural natural frequencies sensitivity analysis of masonry and concrete material parameters, the appropriate modifying parameters were selected and the model of the brick masonry structure was updated [16]. By analyzing the results of ground vibration on shallow buried side and deep buried side, the characteristics of vibration velocity, principal vibration frequency, and safety assessment method were discussed [17].

In this study, a damage assessment of local members of a building near a tunnel excavation is performed using the OMA method. Vibration characteristics are measured during blasting around the building. A complete investigation of damage types and locations of aging masonry buildings is performed by an on-site survey. The initial model of the selected 2-storey masonry structure is constructed, and the analytical frequencies and mode shapes are attained using the ANSYS finite element program. Experimental dynamic characteristics (natural frequencies, mode shapes, and damping ratios) of the structure are determined via the OMA method. Analytical and experimental mode characteristics are compared, and finite element models of the masonry structures are updated by modifying material parameters. Global and local building modes are analyzed using the updated finite element models. The interaction between external blast vibrations, structure global modes, and local modes are analyzed. The dynamic response of local members of masonry structures under blast-induced ground excitations is examined using the updated finite element models. The stresses on various local components in masonry structures in different conditions are studied, and the damage mechanism and location for each masonry structure is obtained.

\section{Description of Tunnel, Blast Vibration Characteristics, and Structural Damage Investigation}

2.1. Tunnel and Surrounding Aging Masonry Buildings. The New Hongyan Tunnel in the Chengdu-Chongqing High-Speed Railway has a length of $6690 \mathrm{~m}$ and is located in the city of Chongqing. The shallow portion of the tunnel is situated at the entrance/exit to the high-speed railway. Tunnel depth varies from 10 to $50 \mathrm{~m}$, approximately. The overlying soils are Quaternary gravel, soil, silt, and clay. The bedrock is composed of alternating mudstone and sandstone layers. $29 \%$ of the surrounding rock is grade $\mathrm{V}$ and $71 \%$ of the surrounding rock is grade IV. Houses are very dense around the tunnel; 2- and 3-storey aging brick houses 
account for most of the structures. Brick houses were built in the 1970s or 1980s. Aging masonry structures are approximately between $16 \mathrm{~m}$ and $40 \mathrm{~m}$ away from the tunnel vault crown. Because brick houses are weak and poor, the vibration induced by tunnel blasting poses a serious threat to the safety of the houses.

2.2. Measurement of Vibration Characteristics. Peak particular velocity (PPV) and dominant frequency (DF) are measured during blasting around the buildings on hard soil to evaluate the effects of blasting on the buildings. Masonry buildings above the tunnel are approximately between $16 \mathrm{~m}$ and $40 \mathrm{~m}$ away from the tunnel vault.

In this study, UBOX-5016 is used for recording vibrations produced in the tunnel. Blasting vibration characteristics are measured by vibration sensors with a biaxial speedometer (vertical and longitudinal). Vibration sensors are located on hard ground in the direction of blasting (Figure 1). Vibration signals are transferred into BM View software to calculate the PPV and DF of each channel.

A total fifty measurements were taken from the tunnel during a 3-month period. Only nine measurements are considered in this study. The tunnel depth, distance away from the blasting center, PPV, and DF of the nine measurements are presented in Table 1 . The velocity is selected as the ground excitation to use in dynamic analyses. The layout of blast holes, initiation time, and different detonators are given in Figure 2. The total charge is approximately $83.6 \sim 96.0 \mathrm{~kg}$. The velocity record and waveform spectrum of $Z$ and $X$ blast vibrations of no. 2 blasting are plotted in Figure 3, which are selected to analyze the response of the masonry structure.

As seen in Table 1, the velocity of blasting vibration using nonelectric detonators is much larger than the velocity of blasting vibration using digital electronic detonators. The structure would probably suffer damage due to over high peak vibration velocity. Therefore, the velocity should be reduced significantly by using digital electronic detonators.

\subsection{Damage Investigation of Masonry Structures due to} Tunnel Blasting. A complete investigation of damage types and locations of masonry buildings due to tunnel blasting vibration is performed by on-site survey. The damage caused by intensive blasting vibration is classified into four types according to the damage location.

2.3.1. Cracking at Stress Concentration Points (Corners). The stress concentration points are the parts of a structure that are most likely to crack under tunnel blasting vibration. Common stress concentration points include door corners, window corners, and wall corners (Figure 4).

2.3.2. Cracking along Floor and Wall Seams. The higher strength and elastic modulus of concrete relative to brick lead to great change in stiffness and uneven force. The stress along the contact between a brick wall and concrete floor is

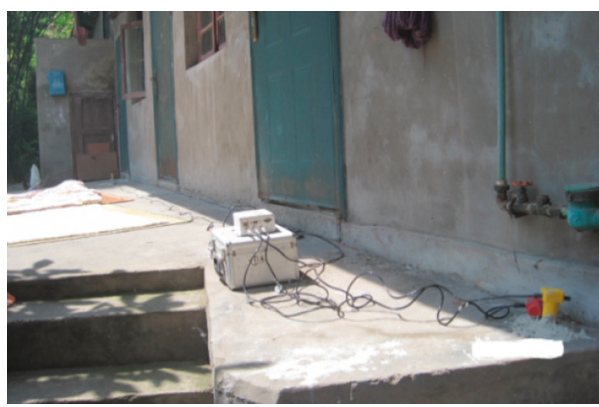

FIgUre 1: Photograph showing the UBOX-5016 instrument and vibration sensors.

greater than other contacts. Cracking of the floor and wall contact is shown in Figure 5.

2.3.3. Cracking of Precast Floors. Precast floors have a significantly different structure from other common floors. Because of use of concrete to grout seal between prefabricated floors without steel connection, it leads to a weak connection between each precast floor section. Because of this weak connection and stiffness mutation, joints between prefabricated floors are prone to cracking under tunnel blasting vibration. Joints may further lead to numerous other negative effects. Rainfall could erode the floor and walls and other appurtenances, as shown in Figure 6.

2.3.4. Cracking of Infilled Walls or Non-Load-Bearing Walls. Because of their lower strength and elastic modulus, infilled walls or non-load-bearing walls are prone to cracking under high transient tensile and shear stress induced by tunnel blasting. Cracking of infilled walls or non-load-bearing walls is shown in Figure 7.

Above all, damage in the masonry structure commonly occurred in local members. The reasons are explored by analyzing the simulation results using the modal analysis method. Before that, the finite element model, which represents the actual dynamic characteristics of the masonry structure, is established and updated based on the results of the OMA test.

\section{Analytical Modal Analyses of the Masonry Building}

3.1. Description of the Masonry Building. The selected masonry building is a two-storey brick concrete building constructed in the early 1980s with a floor area of approximately $200 \mathrm{~m}^{2}$ (Figure 8 ). The selected masonry building is approximately $38 \mathrm{~m}$ away from the tunnel vault. The foundation of the building is strip footing on hard soil ground. The external walls of the building are made of brick and are $24 \mathrm{~cm}$ thick. The floors are made of reinforced concrete with a $15 \mathrm{~cm}$ thickness, and the internal walls are made of clay bricks with a $12 \mathrm{~cm}$ thickness. The clear height is $3.0 \mathrm{~m}$, and the roof is made of reinforced concrete with a $15 \mathrm{~cm}$ thickness. The height of the concrete parapet walls is $70 \mathrm{~cm}$. 
TABle 1: Vibration characteristics of the blasting.

\begin{tabular}{|c|c|c|c|c|c|c|c|}
\hline $\begin{array}{l}\text { Blasting } \\
\text { number }\end{array}$ & $\begin{array}{l}\text { Detonator } \\
\text { type }\end{array}$ & $\begin{array}{l}\text { Tunnel } \\
\text { depth } \\
(\mathrm{m})\end{array}$ & $\begin{array}{c}\text { Distance away } \\
\text { from blasting } \\
\text { center }(\mathrm{m})\end{array}$ & $\begin{array}{l}Z \text { direction peak } \\
\text { particular velocity } \\
(\mathrm{cm} / \mathrm{s})\end{array}$ & $\begin{array}{c}Z \text { direction } \\
\text { dominant } \\
\text { frequency }(\mathrm{Hz})\end{array}$ & $\begin{array}{c}X \text { direction peak } \\
\text { particular velocity } \\
(\mathrm{cm} / \mathrm{s})\end{array}$ & $\begin{array}{c}X \text { direction } \\
\text { dominant } \\
\text { frequency }(\mathrm{Hz})\end{array}$ \\
\hline 1 & Nonelectric & 17.9 & 30.7 & 2.974 & 70.80 & 0.761 & 20.75 \\
\hline 2 & Nonelectric & 18.2 & 32.6 & 2.227 & 76.90 & 0.807 & 21.97 \\
\hline 3 & Electronic & 17.5 & 29.2 & 1.940 & 46.99 & 0.651 & 11.60 \\
\hline 4 & Electronic & 37.6 & 43.1 & 1.395 & 92.77 & 0.975 & 64.70 \\
\hline 5 & Electronic & 35.6 & 41.8 & 1.003 & 77.52 & 0.269 & 62.26 \\
\hline 6 & Electronic & 22.9 & 31.1 & 1.307 & 141.60 & 0.858 & 62.86 \\
\hline 7 & Electronic & 18.6 & 30.5 & 1.376 & 137.94 & 0.676 & 87.89 \\
\hline 8 & Electronic & 17.9 & 29.2 & 1.023 & 78.74 & 0.622 & 62.87 \\
\hline 9 & Electronic & 16.9 & 28.0 & 0.902 & 76.90 & 0.590 & 22.50 \\
\hline
\end{tabular}

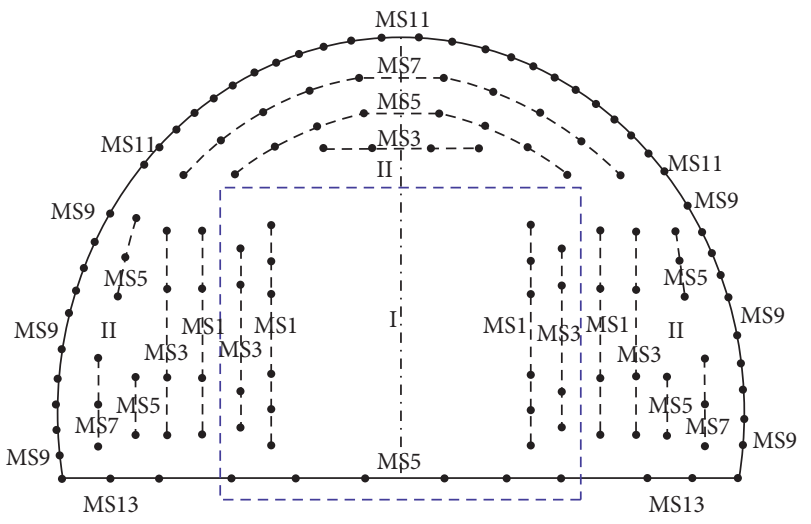

(a)

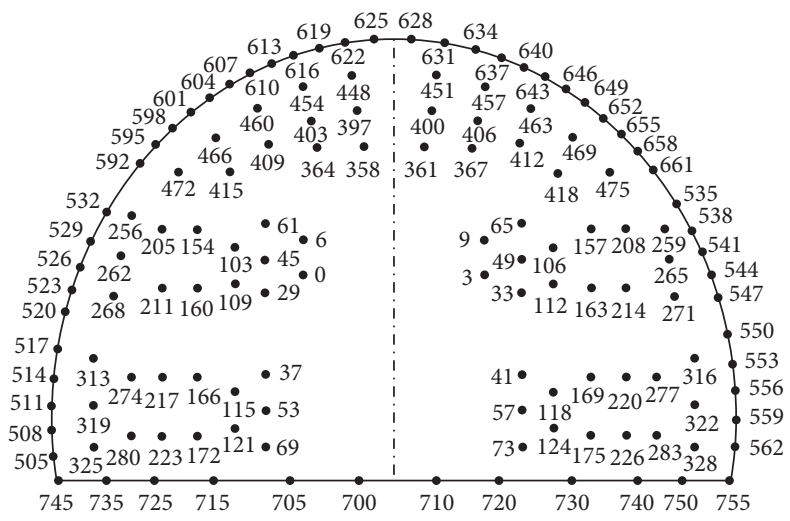

(b)

FIgURE 2: Layout of blast holes and initiation time (unit: ms). (a) Using nonelectric detonator. (b) Using digital electronic detonator.

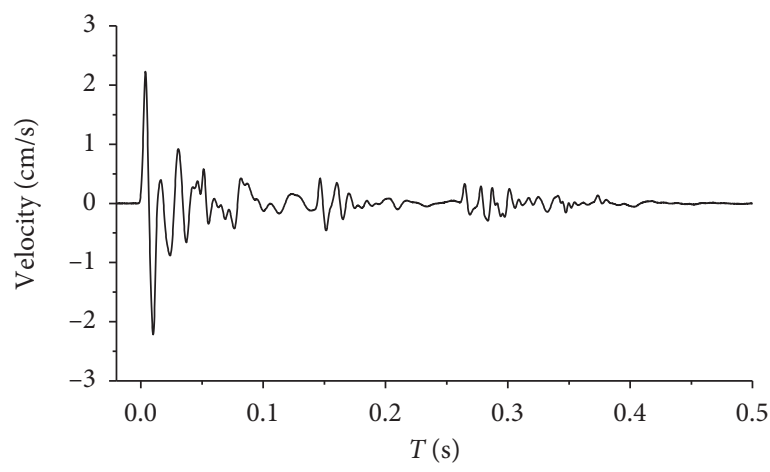

(a)

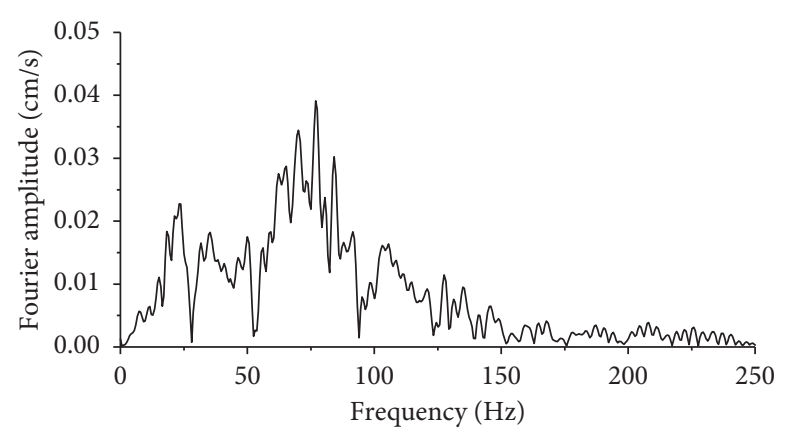

(c)

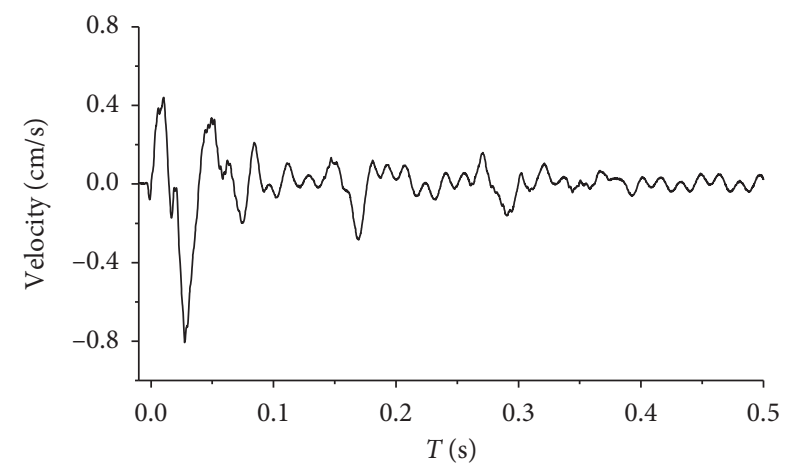

(b)

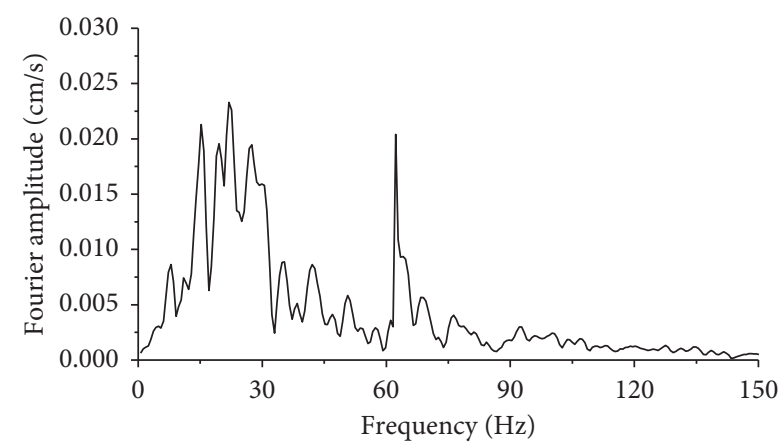

(d)

Figure 3: Time history of velocity and Fourier amplitude of $Z$ and $X$ blast vibrations. (a) $Z$ direction blast vibration. (b) $X$ direction blast vibration. (c) $Z$ direction blast vibration Fourier amplitude. (d) $X$ direction blast vibration Fourier amplitude. 


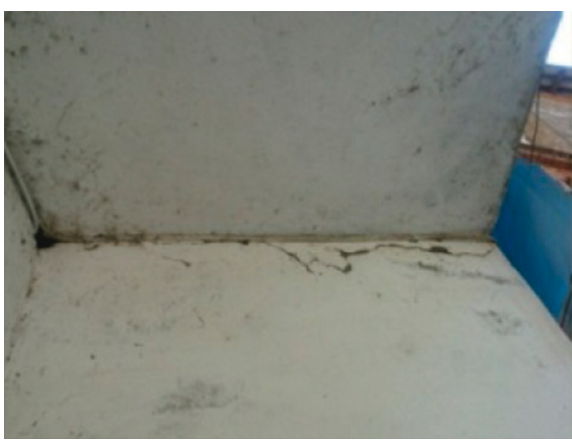

(a)

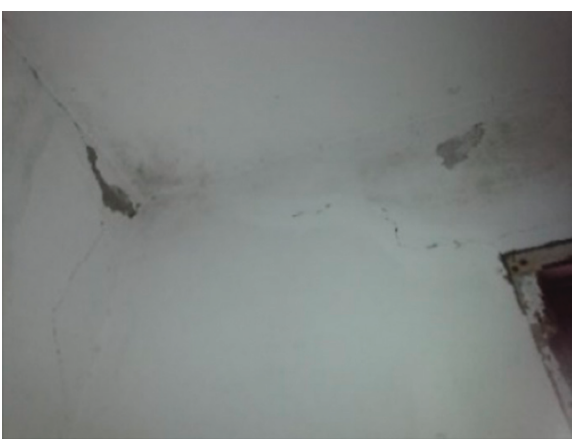

(b)

Figure 4: Cracks of the stress concentrated area.

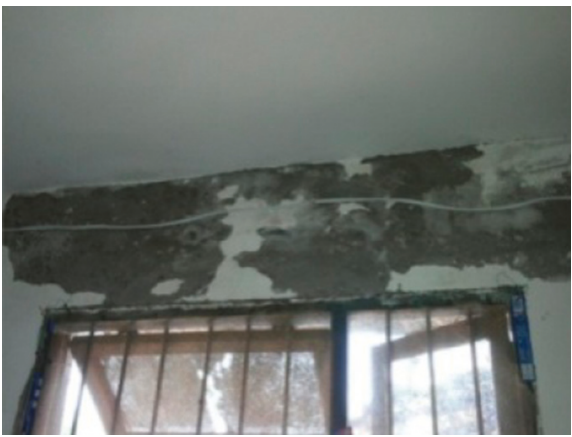

(a)

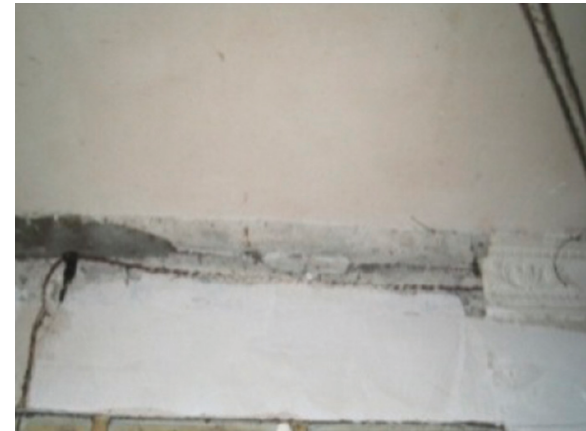

(b)

FIgURE 5: Cracks of floor and wall contact area.

3.2. Analytical Model of the Initial Masonry Building. The analytical model for the masonry building is constituted using the ANSYS finite element program. Modal analysis of the building is carried out to calculate natural frequencies and mode shapes. The analytical model is created after an in situ investigation of the building's structure. In the analytical model, columns, walls, beams, and other members are modeled using solid elements with six degrees of freedom in each node (translation in $x, y$, and $z$ directions; rotation around the $x, y$, and $z$ axes) (Figure 9). The live loads are not considered in the analytical model.

The mechanical properties of the building materials are given in Table 2. It is difficult to determine the exact values of mechanical properties for the building materials. In the study, values are first determined according to the concrete classification and taken from building code and semiempirical equations. Then, the values of mechanical properties of materials are updated using the model updating method.

It is assumed that all degrees of freedom of the base points are fixed, and the first four natural frequencies and corresponding mode shapes are calculated. The first four natural frequencies range between 9 and $23 \mathrm{~Hz}$. The first mode of the building is a first-order longitudinal buckling. The second mode is a first-order transverse buckling. The third mode is torsion, and the fourth mode is a second-order longitudinal buckling.

\section{OMA Test and Model Updating of the Structure}

4.1. OMA Test and Experimental Modes. There are two different test methods available to experimentally identify dynamic system parameters of a structure, experimental modal analysis (EMA) and OMA [18]. In OMA, an unknown input force excites the structure, and the response of the structure is measured. A system identification procedure will therefore be needed to base itself on output-only data [19]. Frequency domain output-only modal identification method, like the EFDD, is applied to this test. In this study, experimental modes (natural frequencies, mode shapes, and modal damping ratios) of the building are determined from the OMA test. Vibrations produced from tunnel blasting are used as the vibration source. Because of the wide frequency range and high energy of tunnel blasting, more modes can be excited relative to using ambient vibration. An ambient vibration test was conducted on the building by placing six uniaxial (longitudinal) speedometers to the corners of each floor (Figures 10 and 11).

An 8-channel data logger (INV3060S) is used for acquiring the signals from the speedometers. Signals are transferred into a DASP program in the laptop via cross cable. Signals are transferred from the DASP program to obtain modal parameters. Tests are approximately 5 minutes long. Therefore, measurement begins at least 2 minutes 


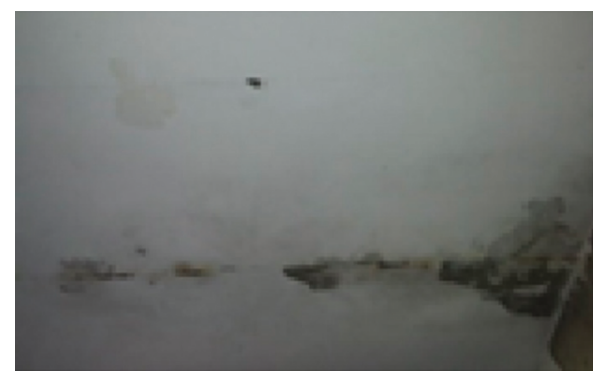

(a)

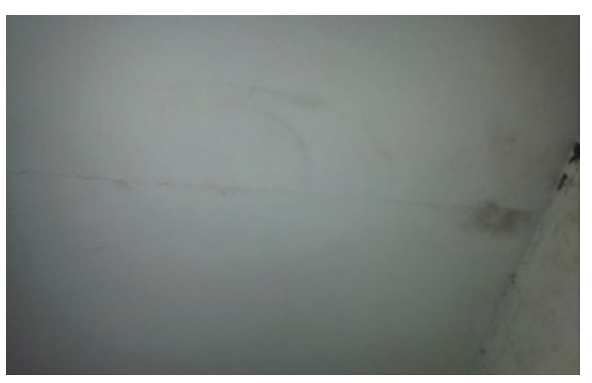

(b)

Figure 6: Cracks of precast floor slab joint.

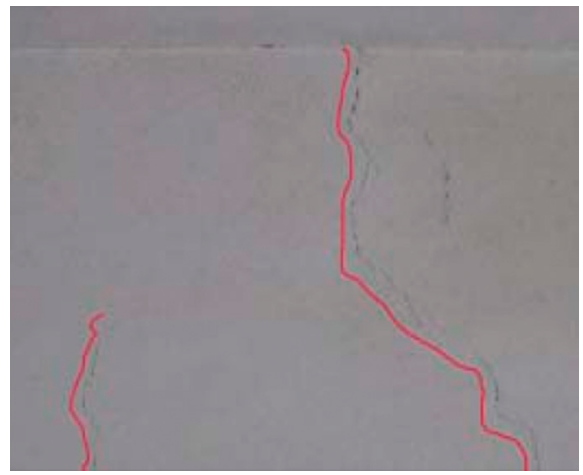

(a)

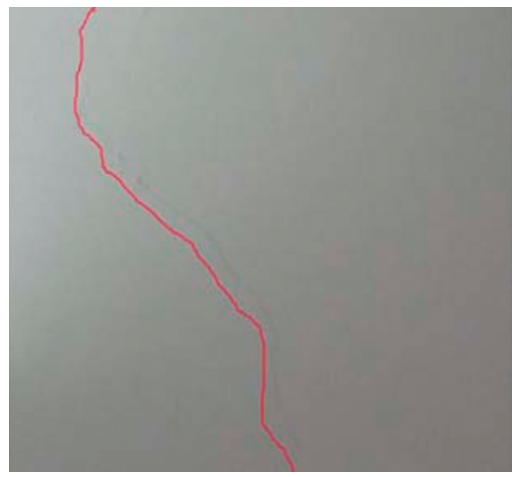

(b)

FIgURE 7: Cracking of infilled walls.

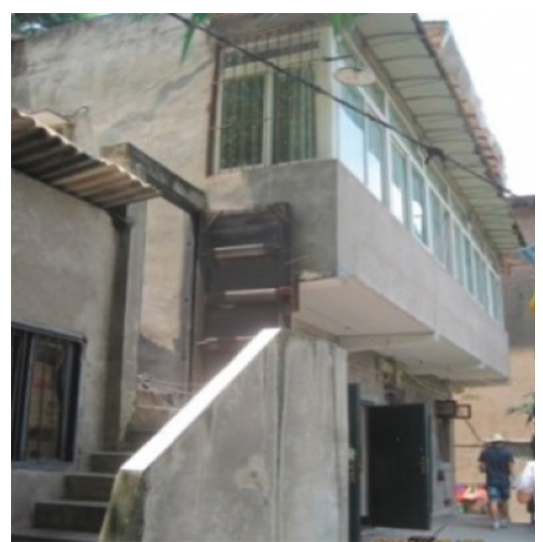

(a)

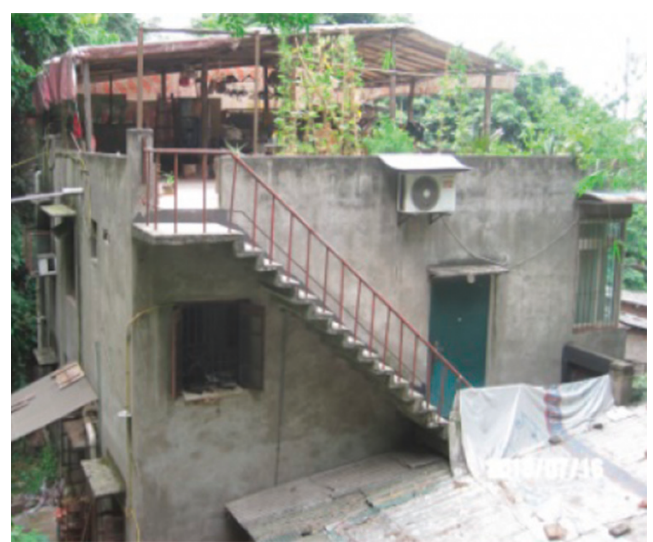

(b)

Figure 8: Photographs showing the two-storey masonry building.

before blasting and continued after blasting. A typical signal recorded in test is given in Figure 12. Also, the autospectra for this signal are given in Figure 13. The frequency response function obtained from the EFDD technique is given in Figure 14. The natural frequencies are selected using the peak picking method given in Table 3 .

The purpose of the OMA test is to identify the natural frequencies and mode shapes, which can be used to update the initial analytical model. Due to the limited number of measurement points, it is difficult to obtain the higher local modes for large buildings. The first through fourth global modes are acquired easily, and the initial analytical model is updated based on these modes.

4.2. Updating the Finite Element Model Structure. Analytical dynamic characteristics do not coincide with experimental characteristics. These discrepancies mainly 


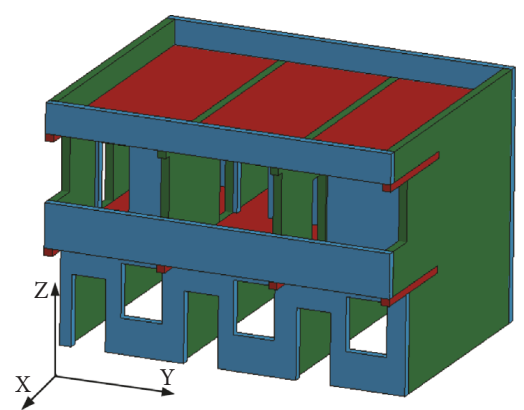

(a)

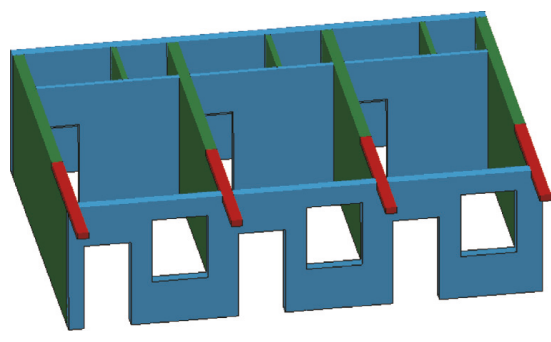

(b)

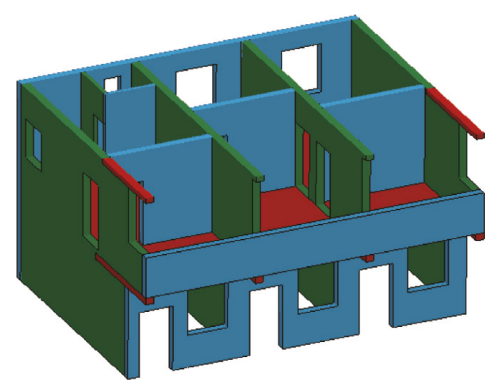

(c)

Figure 9: Analytical model of the masonry building. (a) Masonry building. (b) Section of the first floor. (c) Section of the second floor.

TABLE 2: Mechanical properties of building materials.

\begin{tabular}{lcccc}
\hline Material & Density $\left(\mathrm{kg} / \mathrm{m}^{3}\right)$ & Modulus of elasticity $(\mathrm{GPa})$ & Modulus of shear $(\mathrm{GPa})$ & Poisson ratio \\
\hline Masonry & 1800 & 2.70 & 1.08 & 0.15 \\
Concrete & 2300 & 23.75 & 9.50 & 0.20 \\
\hline
\end{tabular}

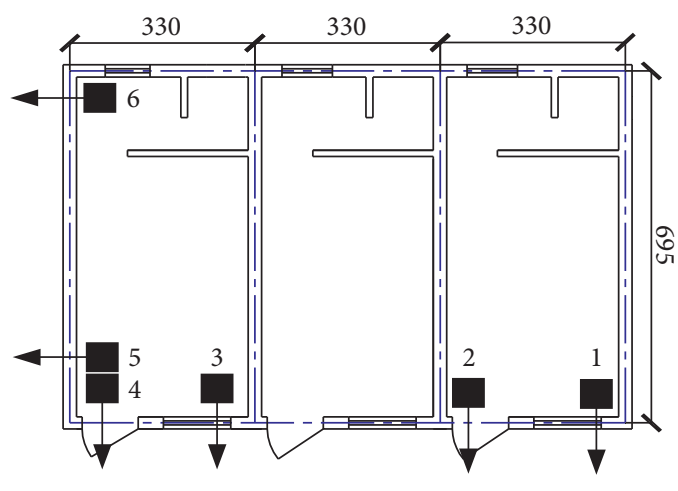

(a)

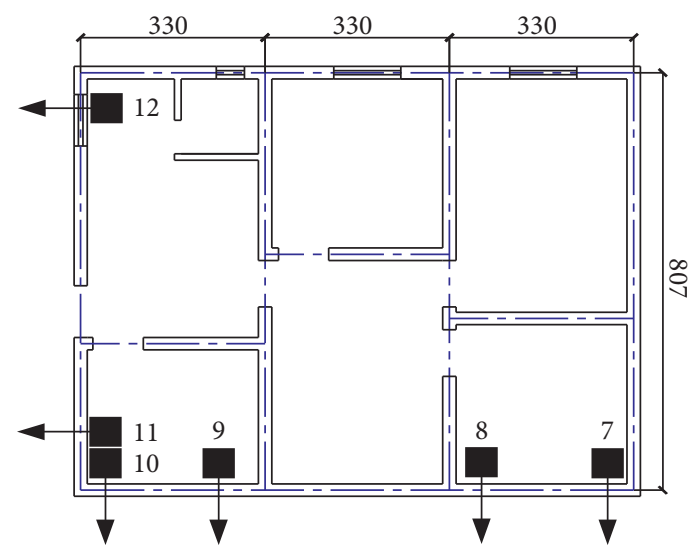

(b)

Figure 10: Schematic diagram showing the layout of the measurement points (unit: $\mathrm{cm}$ ). (a) First floor. (b) Second floor.
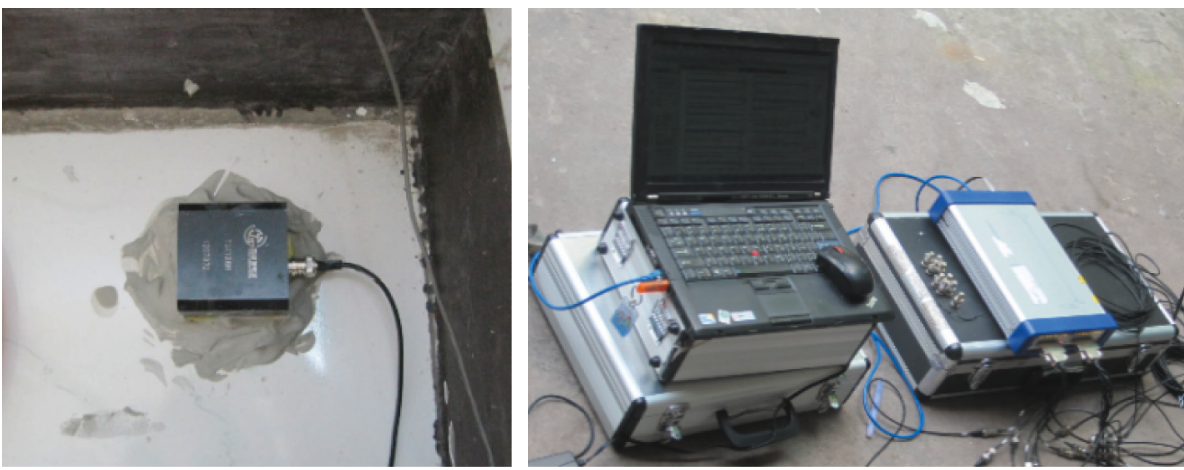

FIGURE 11: Photographs showing measurement equipment.

originate from the uncertainties in the materials and inaccurate boundary conditions. The main purpose of the model updating procedure is to minimize differences between analytical and experimental dynamic characteristics by varying uncertainty parameters such as material properties and boundary conditions [20]. In the literature, many studies can be found on the finite element model updating [21-25]. The model updating process typically consists of 


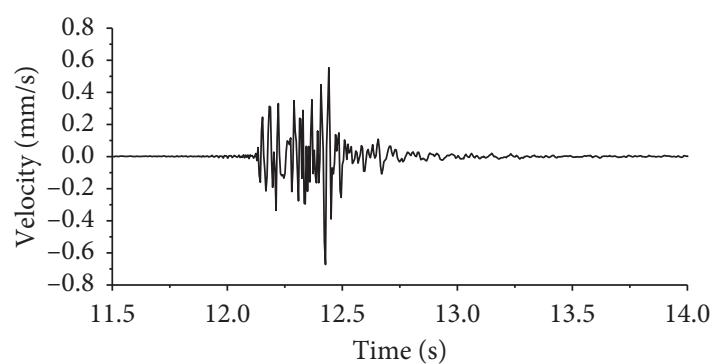

Figure 12: A typical recorded test signal (no. 1).

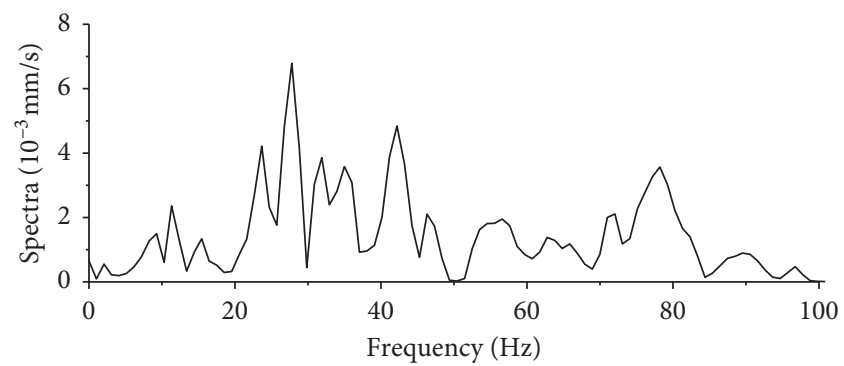

FIgURE 13: Autospectra of a recorded signal (no. 1).

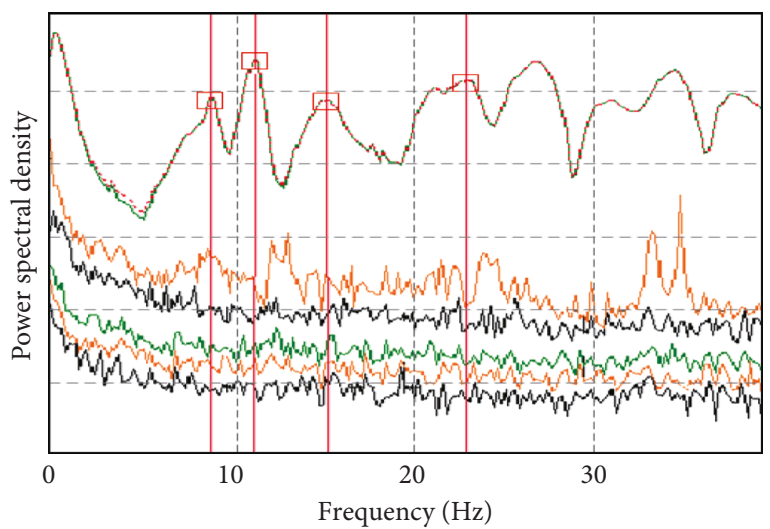

FIGURE 14: The frequency response function obtained from the EFDD technique.

TABLE 3: Modal parameters of masonry building under tunnel blasting vibration.

\begin{tabular}{lcc}
\hline Mode number & Frequency $(\mathrm{Hz})$ & Damping ratio $(\%)$ \\
\hline 1 & 9.224 & 3.11 \\
2 & 11.596 & 3.52 \\
3 & 15.640 & 5.79 \\
4 & 25.351 & 4.23 \\
\hline
\end{tabular}

manual tuning and automatic model updating using ANSYS software. Since the finite element model of the building is constructed based on the project data and on-site measurements, discrepancies are mainly derived from material parameters due to degradation of the masonry walls over time. According to the first four modal parameters obtained from the OMA ambient vibration test, the appropriate modified masonry and concrete material parameters are selected for updating the model of the brick masonry structure. The aim of this is to bring the numerical model closer to the experimental results. The manual tuning procedure is used for updating the finite element model.

Because the number of updating material parameters is larger than the four known modal parameters, a proper objective function is minimized to acquire the optimal material parameters using the manual tuning procedure. Therefore, the model updating objective function is

$$
\text { MBHS }=\min \sum_{i=1}^{4}\left(\frac{f_{\mathrm{ei}}-f_{\mathrm{ai}}}{f_{\mathrm{ei}}}\right)^{2} .
$$

In equation (1), MBHS is the objective function, $f_{\mathrm{ei}}$ is the experimental natural frequency, and $f_{\mathrm{ai}}$ is the analytical natural frequency.

The model updating of the masonry structure has been achieved by Guan [26]. The results can be used in this paper. The natural frequencies obtained from the initial and updated analytical models are given in Table 4.

After changing the material parameters, the updated model is taken as the model that best represents the actual building. The local modes, dynamic response, and damage analysis are based on this updated model.

\section{Modes of the Updated Model and Interaction between Blast Vibrations and the Structure}

5.1. Global and Local Modes of the Updated Model. The building modes can be separated into global modes and local modes. Global modes are characterized by uniform deformation in the main structure. Local modes are characterized by relatively little deformation in the main structure and greater deformation in the local floor and shell. Local deformation is much larger than global deformation in local modes. Local modes are easily obtained by comparing the finite element modal analysis with the experimental method. Global modes and local modes of the masonry building are obtained by using ANSYS to carry out finite element modal analysis.

The first 20 natural frequencies of the structure range from $8.80-36.34 \mathrm{~Hz}$. The dynamic characteristics of lower order global modes and higher order local modes of the masonry building are as follows:

(1) The first through fifth natural frequencies of the structure range from $8.80-24.99 \mathrm{~Hz}$ (Table 5). Take the first through fourth-order global modes as examples; their deformations are first-order longitudinal buckling, first-order transverse buckling, torsion, and second-order longitudinal buckling (Figure 10). Above all, the global modes show uniform deformation.

(2) The sixth through 20th natural frequencies of the structure range from $26.10-36.34 \mathrm{~Hz}$ (Table 5). In higher order local modes, vibration characteristics are not uniform, and local deformation is much 
TABLe 4: Natural frequencies of the masonry building for initial and updated models.

\begin{tabular}{lccc}
\hline Mode number & & Natural frequencies (Hz) & \\
& Updated analytical model & Experimental \\
\hline 1 & 9.026 & 8.804 & 9.185 \\
2 & 13.060 & 12.457 & 11.708 \\
3 & 16.143 & 15.989 & 15.655 \\
4 & 23.698 & 23.123 & 25.118 \\
\hline
\end{tabular}

TABLe 5: Natural frequencies of the masonry building for initial and updated models.

\begin{tabular}{|c|c|c|}
\hline Modal no. & Frequency $(\mathrm{Hz})$ & Modal shape \\
\hline 1 & 8.80 & First-order buckling longitudinal global deformation \\
\hline 2 & 12.46 & First-order transverse buckling global deformation \\
\hline 3 & 15.99 & Torsion global deformation \\
\hline 4 & 23.12 & $\begin{array}{c}\text { Second-order longitudinal buckling global } \\
\text { deformation }\end{array}$ \\
\hline 5 & 24.99 & Second-order transverse buckling global deformation \\
\hline 6 & 26.10 & $\begin{array}{c}\text { Left side wall of second floor and front parapet wall } \\
\text { local deformation }\end{array}$ \\
\hline 7 & 26.55 & Right side wall of second floor local deformation \\
\hline 8 & 28.71 & Right side wall of second floor local deformation \\
\hline 9 & 29.91 & $\begin{array}{l}\text { Longitudinal partition wall of first floor and front } \\
\text { parapet wall local deformation }\end{array}$ \\
\hline 10 & 30.09 & $\begin{array}{c}\begin{array}{c}\text { Longitudinal partition wall of first floor local } \\
\text { deformation }\end{array}\end{array}$ \\
\hline 11 & 30.16 & $\begin{array}{c}\text { Longitudinal partition wall of first floor local } \\
\text { deformation }\end{array}$ \\
\hline 12 & 30.38 & $\begin{array}{c}\text { Transverse partition wall of second floor and front } \\
\text { parapet wall local deformation }\end{array}$ \\
\hline 13 & 31.30 & $\begin{array}{c}\text { Right side wall and transverse partition wall of second } \\
\text { floor local deformation }\end{array}$ \\
\hline 14 & 31.54 & $\begin{array}{l}\text { Front parapet wall, right side wall, and transverse } \\
\text { partition wall of second floor local deformation }\end{array}$ \\
\hline 15 & 32.55 & $\begin{array}{l}\text { Front parapet wall, right side wall, and transverse } \\
\text { partition wall of second floor local deformation }\end{array}$ \\
\hline 16 & 32.97 & $\begin{array}{c}\text { Front parapet wall, transverse wall of first floor, and } \\
\text { transverse partition wall of second floor local } \\
\text { deformation }\end{array}$ \\
\hline 17 & 33.60 & $\begin{array}{l}\text { Partition wall of second floor, balcony, and front } \\
\text { parapet wall local deformation }\end{array}$ \\
\hline 18 & 33.98 & Balcony and front parapet wall local deformation \\
\hline 19 & 35.47 & $\begin{array}{l}\text { Balcony, transverse partition wall of second floor, and } \\
\text { right window side wall local deformation }\end{array}$ \\
\hline 20 & 36.34 & $\begin{array}{l}\text { Balcony, transverse partition wall of second floor, and } \\
\text { right window side wall local deformation }\end{array}$ \\
\hline
\end{tabular}

greater than global deformation in locations such as the front parapet wall, longitudinal partition wall, side wall, partition wall, and balcony. Consider the sixth-, seventh-, eighth-, thirteenth-, fourteenth-, and nineteenth-order local modes as examples: the local deformation of the second floor left side wall, front parapet wall, first floor longitudinal partition wall, right side wall, second floor partition wall, and balcony is much greater than the global deformation (Figure 15).

5.2. Modal Analyses of Local Members of the Building. In local modes of the building, local deformation in the side wall, partition wall, and parapet wall (structure's prominent part) is much greater than the main structure. In this study, by establishing two numerical models, the natural frequencies of the above local members are calculated. In order to simplify the analysis, masonry is assumed to be isotropic. The density of masonry is $1800 \mathrm{~kg} / \mathrm{m}^{3}$, elastic modulus is 2.5E9Pa, and Poisson's ratio is 0.15 . With regard to the side wall or partition wall, it is assumed that $X, Y$, and $Z$ degrees of freedom of the base points are fixed, and $X$ and $Y$ degrees of freedom of top points are fixed. With regard to the parapet wall (structure's prominent part), it is assumed that $X, Y$, and $Z$ degrees of freedom of base points are fixed. The natural frequencies of above two local members are calculated and given in Table 6. 


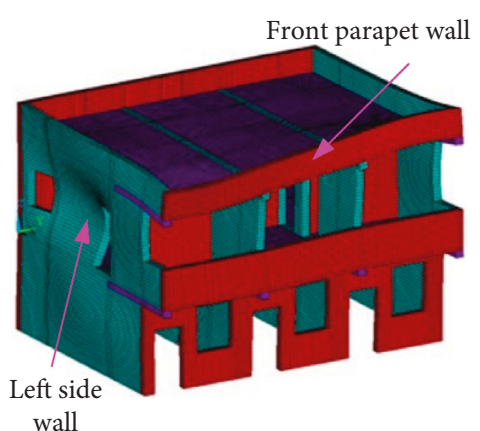

(a)

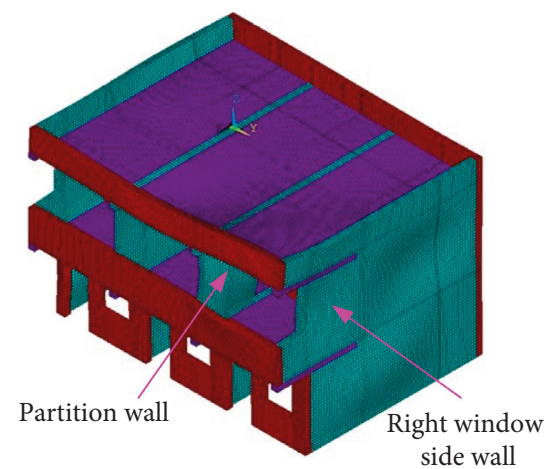

(d)

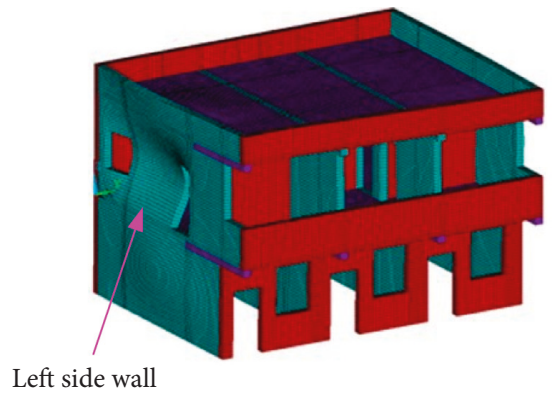

(b)

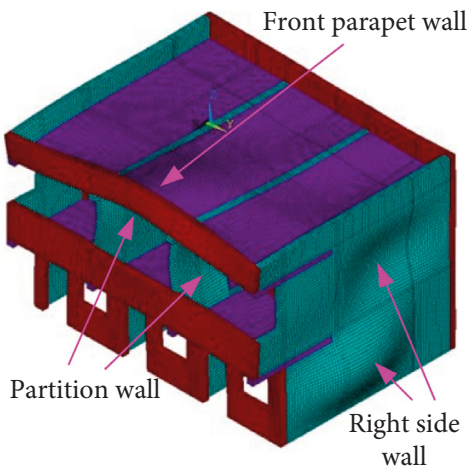

(e)

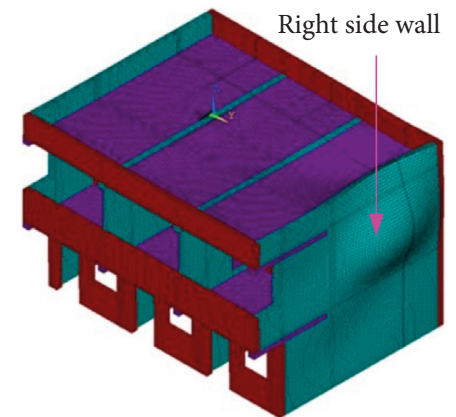

(c)

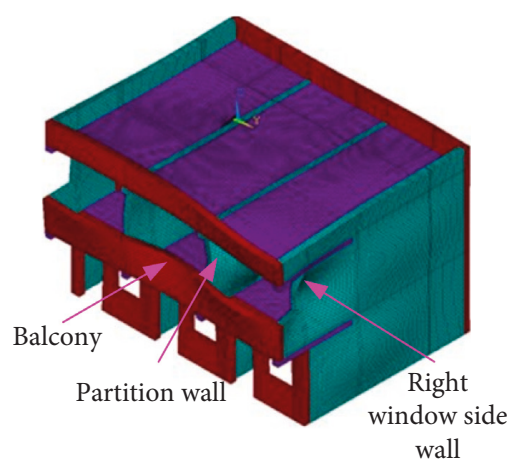

(f)

Figure 15: Local modal shapes of the masonry building [13]. (a)Mode $6\left(f_{6}=26.10 \mathrm{~Hz}\right)$. (b) Mode $7\left(f_{6}=26.55 \mathrm{~Hz}\right)$. (c) Mode 8 $\left(f_{6}=28.71 \mathrm{~Hz}\right)$. (d) Mode $13\left(f_{6}=31.30 \mathrm{~Hz}\right)$. (e) Mode $14\left(f_{6}=31.54 \mathrm{~Hz}\right)$. (f) Mode $19\left(f_{6}=35.47 \mathrm{~Hz}\right)$.

TABLE 6: First through 10th natural frequencies of the building's side wall and parapet wall.

\begin{tabular}{|c|c|c|c|c|c|c|c|c|c|c|}
\hline Local member & 1 & 2 & 3 & 4 & 5 & 6 & 7 & 8 & 9 & 10 \\
\hline Side wall $(\mathrm{Hz})$ & 21.94 & 37.57 & 68.70 & 88.92 & 93.27 & 93.57 & 98.38 & 136.84 & 146.16 & 157.55 \\
\hline Parapet wall $(\mathrm{Hz})$ & 5.09 & 17.44 & 31.05 & 33.56 & 56.81 & 75.94 & 84.15 & 98.38 & 110.20 & 112.59 \\
\hline
\end{tabular}

The first through 10th natural frequencies of the side wall and parapet wall range from $21.94-157.55 \mathrm{~Hz}$ and $5.09-$ $112.59 \mathrm{~Hz}$, respectively. The modal shapes of side wall and parapet wall are given in Figures 16 and 17, respectively. In contrast with the first through 20th natural frequencies of the building $(8.80-36.14 \mathrm{~Hz})$, the natural frequencies of local members are much larger than the overall building.

\subsection{Interaction between External Blast Vibration Frequency} and Structural Modes. Different members, such as loadbearing walls, cantilever beams, floor, partition walls, side walls, parapet walls, and balconies, compose the masonry building. Global or local vibration modes depend on the dominant frequencies of external ground motion. The interaction between external ground motion and structure modes is given in Figure 18.

From Figure 18, the interaction between external ground motion and structure modes is as follows:

(1) If the dominant external ground motion frequencies are close to global mode natural frequencies, the members will vibrate in those global modals and appear to have uniform and global deformation. Consider the earthquake as an example: since the frequency of the earthquake is $0-10 \mathrm{~Hz}$, it will lead to the global deformation and global collapse.

(2) If the dominant external ground motion frequencies are close to local mode natural frequencies, members will vibrate in those local modals and appear to have different deformation. Under high-frequency ground motion, local members, such as the front parapet wall, longitudinal partition wall, side wall, partition wall, and balcony, appear to record greater deformation than the global structure.

(3) Seismic waves induced by shallow tunnel blasts are commonly high frequency. As given in Table 1, the principal frequencies of tunnel blast vibration are mostly higher than the natural global structural frequencies of the structure and close to the natural frequencies of local members. It follows that local members would experience intensive vibration. In other words, high-frequency ground motion induced by tunnel blasting will cause intensive vibration and local damage of local members. This is consistent 


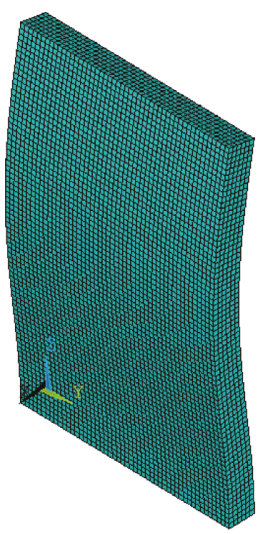

(a)

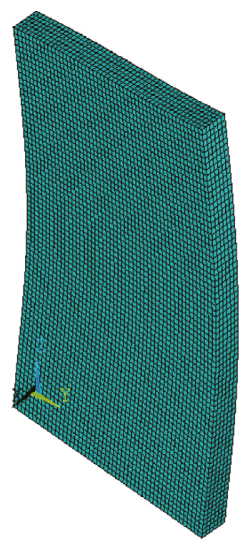

(f)

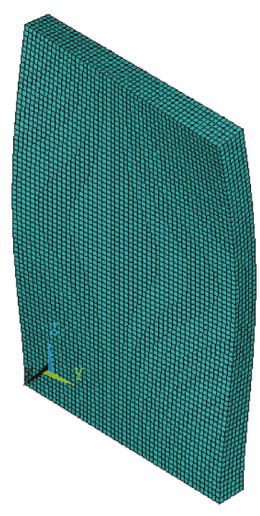

(b)

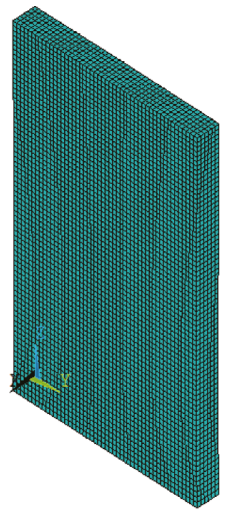

(g)

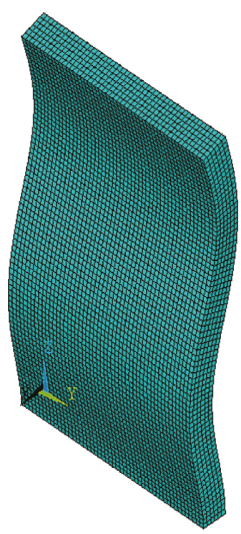

(c)

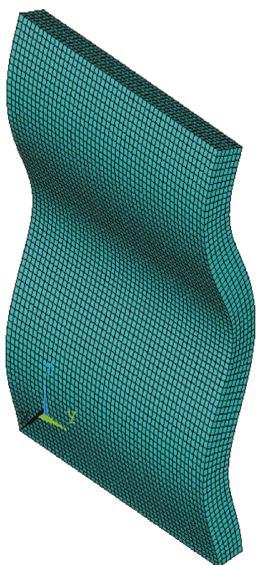

(h)

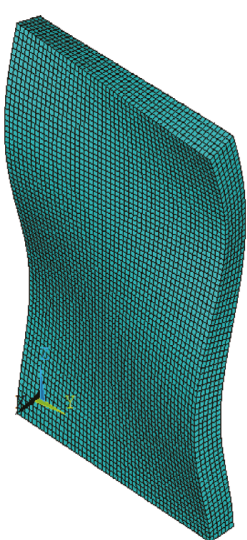

(d)

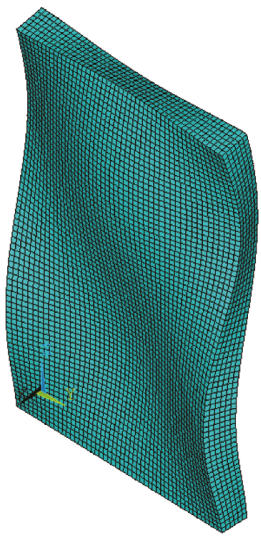

(i)

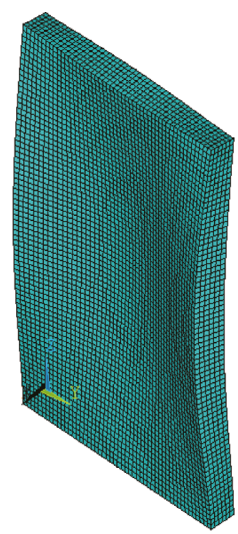

(e)

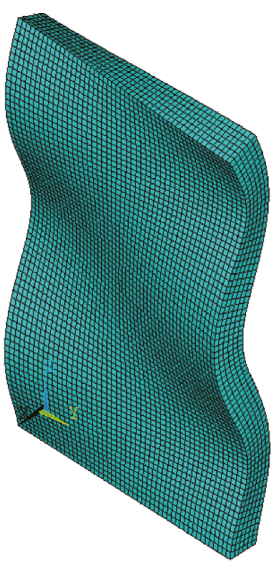

(j)

Figure 16: Modal shapes of side wall of the building. (a) Mode $1\left(f_{1}=21.94 \mathrm{~Hz}\right)$. (b) Mode $2\left(f_{2}=37.57 \mathrm{~Hz}\right)$. (c) Mode $3\left(f_{3}=68.70 \mathrm{~Hz}\right)$. (d) Mode $4\left(f_{4}=88.92 \mathrm{~Hz}\right)$. (e) Mode $5\left(f_{5}=93.27 \mathrm{~Hz}\right)$. (f) Mode $6\left(f_{6}=93.57 \mathrm{~Hz}\right)$. (g) Mode $7\left(f_{7}=98.38 \mathrm{~Hz}\right)$. (h) Mode $8\left(f_{8}=136.84 \mathrm{~Hz}\right)$. (i) Mode $9\left(f_{9}=146.16 \mathrm{~Hz}\right)$. (j) Mode $10\left(f_{10}=157.55 \mathrm{~Hz}\right)$.

with the local damage found in aging buildings at the site. Therefore, in order to investigate the masonry damage mechanism under blast vibration, it is important to focus on the dynamic response of local members of the masonry building.

\section{Dynamic Responses and Damage Mechanisms of Local Members of the Masonry Building}

6.1. Theoretical Analysis of Structural Dynamic Response. For any modal component $v_{n}$, the displacement is given by the product of the mode-shape vector $\phi_{n}$ and the modal amplitude $Y_{n}$; thus,

$$
v_{n}=\phi_{n} Y_{n}(t)
$$

The total displacement vector $v$ is obtained by summing the modal vectors as expressed by

$$
v(t)=\phi_{1} Y_{1}(t)+\phi_{2} Y_{2}(t)+\cdots+\phi_{N} Y_{N}(t)=\sum_{n=1}^{N} \phi_{n} Y_{n}(t)
$$

where $\phi_{n}$ is the vector model and $Y_{n}(t)$ are coordinates of the vector.

It should be noted that for most types of lower frequency loading, displacement is generally greatest for lower modes and tends to decrease for higher modes. Therefore, it is usually not necessary to include higher vibration modes in the superposition calculation. However, for high-frequency loading, higher vibration modes should be taken into superposition calculation.

The stresses or forces developed in various structural components can be evaluated directly from the displacements. The elastic forces $f_{s}$, which resist deformation of the structure, are given by reference [27].

$$
\begin{aligned}
f_{\mathrm{S}}(t) & =k v(t)=k \Phi Y(t), \\
f_{\mathrm{S}}(t) & =\omega_{1}^{2} m \phi_{1} Y_{1}(t)+\omega_{2}^{2} m \phi_{2} Y_{2}(t)+\cdots+\omega_{N}^{2} m \phi_{N} Y_{N}(t) \\
& =\sum_{n=1}^{N} \omega_{n}^{2} m \phi_{n} Y_{n}(t),
\end{aligned}
$$

where $m$ is mass, $k$ is stiffness, and $w_{n}$ is the natural frequency. $w_{n}^{2} Y_{n}(t)$ represents a vector of modal amplitudes each multiplied by the square of its modal frequency. 


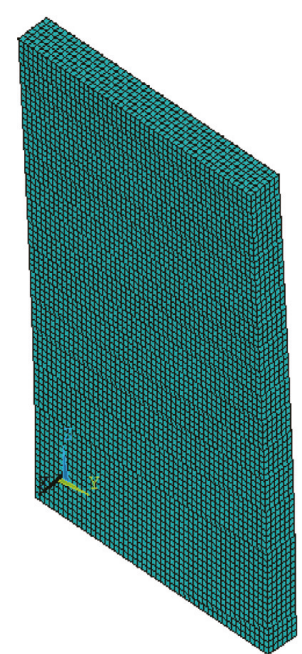

(a)

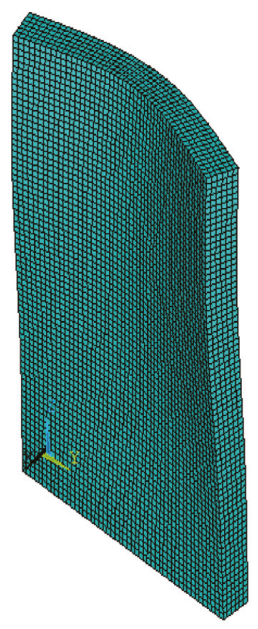

(f)

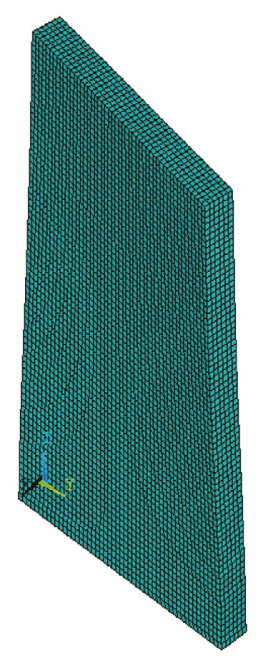

(b)

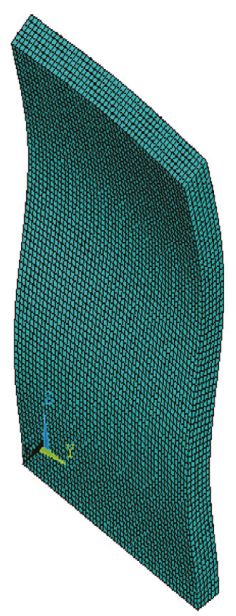

(g)

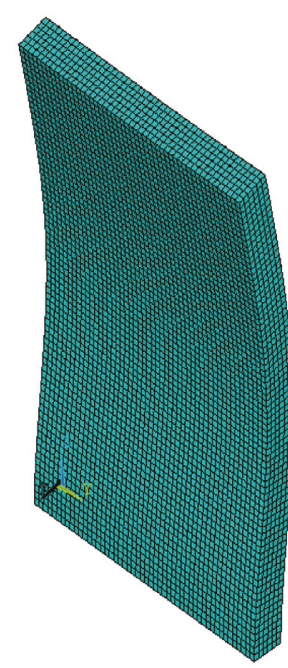

(c)

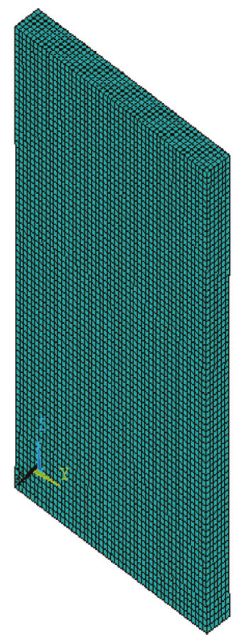

(h)

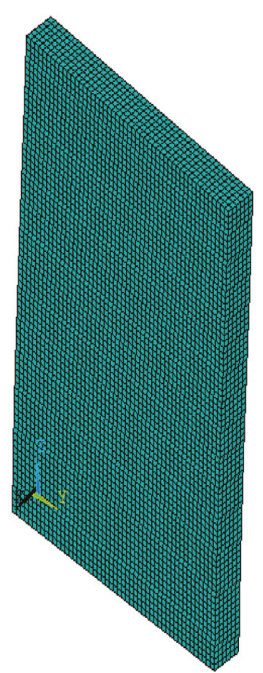

(d)

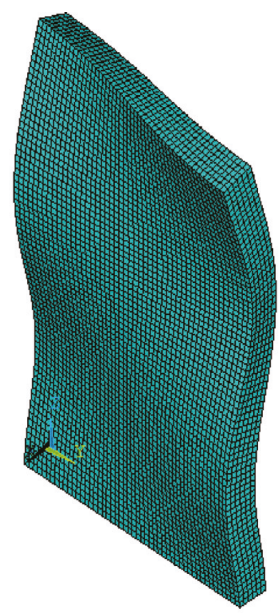

(i)

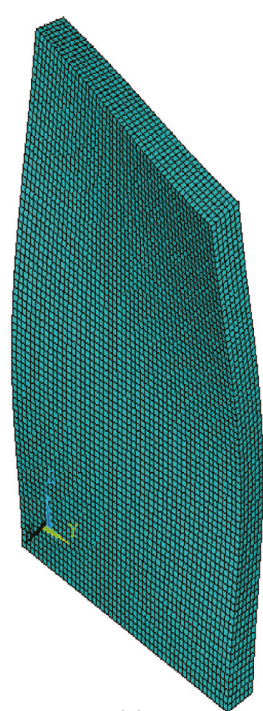

(e)

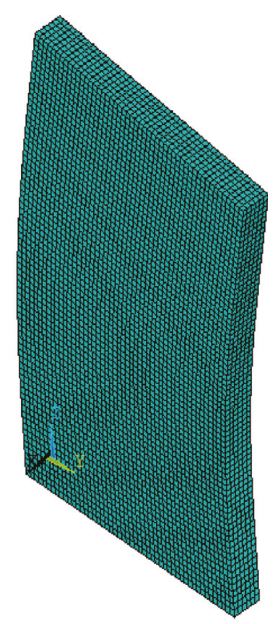

(j)

Figure 17: Modal shapes of parapet wall of the building. (a) Mode $1\left(f_{1}=5.09 \mathrm{~Hz}\right)$. (b) Mode $2\left(f_{2}=17.44 \mathrm{~Hz}\right)$. (c) Mode $3\left(f_{3}=31.05 \mathrm{~Hz}\right)$. (d) Mode $4\left(f_{4}=33.56 \mathrm{~Hz}\right)$. (e) Mode $5\left(f_{5}=56.81 \mathrm{~Hz}\right)$. (f) Mode $6\left(f_{6}=75.94 \mathrm{~Hz}\right)$. (g) Mode $7\left(f_{7}=84.15 \mathrm{~Hz}\right)$. (h) Mode $8\left(f_{8}=98.38 \mathrm{~Hz}\right)$. (i) Mode $9\left(f_{9}=110.20 \mathrm{~Hz}\right)$. (j) Mode $10\left(f_{10}=112.59 \mathrm{~Hz}\right)$.

Because each modal contribution is multiplied by the square of the modal frequency in equation (5), it is evident that higher modes are of greater significance in defining the forces in the structure than they are in defining the displacements. Consequently, it will be necessary to include more modal components to define the forces than to define the displacements [27]. The stress response is much more significant than displacement response for a structure under high-frequency ground motion induced by tunnel blasting. It is better to investigate masonry damage by analyzing the stress with the structure.

\subsection{Dynamic Response of Local Members of the Masonry Building}

6.2.1. Masonry Failure Modes. In order to investigate the change in stress of the masonry structure, high and low principal frequency seismic waves are applied only in one direction or two directions at the base of the building. Stresses on local members and main structural components are obtained by using LS-DYNA to perform a dynamic analysis. Regardless of floor live loads, dead loads, and blast vibration loads, the final calculated stress response is induced by gravity and blasting loads.

The masonry failure can be divided into three different modes (Figure 19). Mode I has positive hydrostatic pressure $(p>0)$ and leads to failure due to mortar tension. Mode II is defined by intermediate compression induced by mortar and brick shear. Mode III is defined by compression $\left(p<p_{1}\right)$, corresponding to brick compressive failure. The damage within the masonry structure is governed by the tensile stress of local members. It is assumed that the maximum principal tensile stresses of local members exceed the ultimate tensile strength of the mortar. 


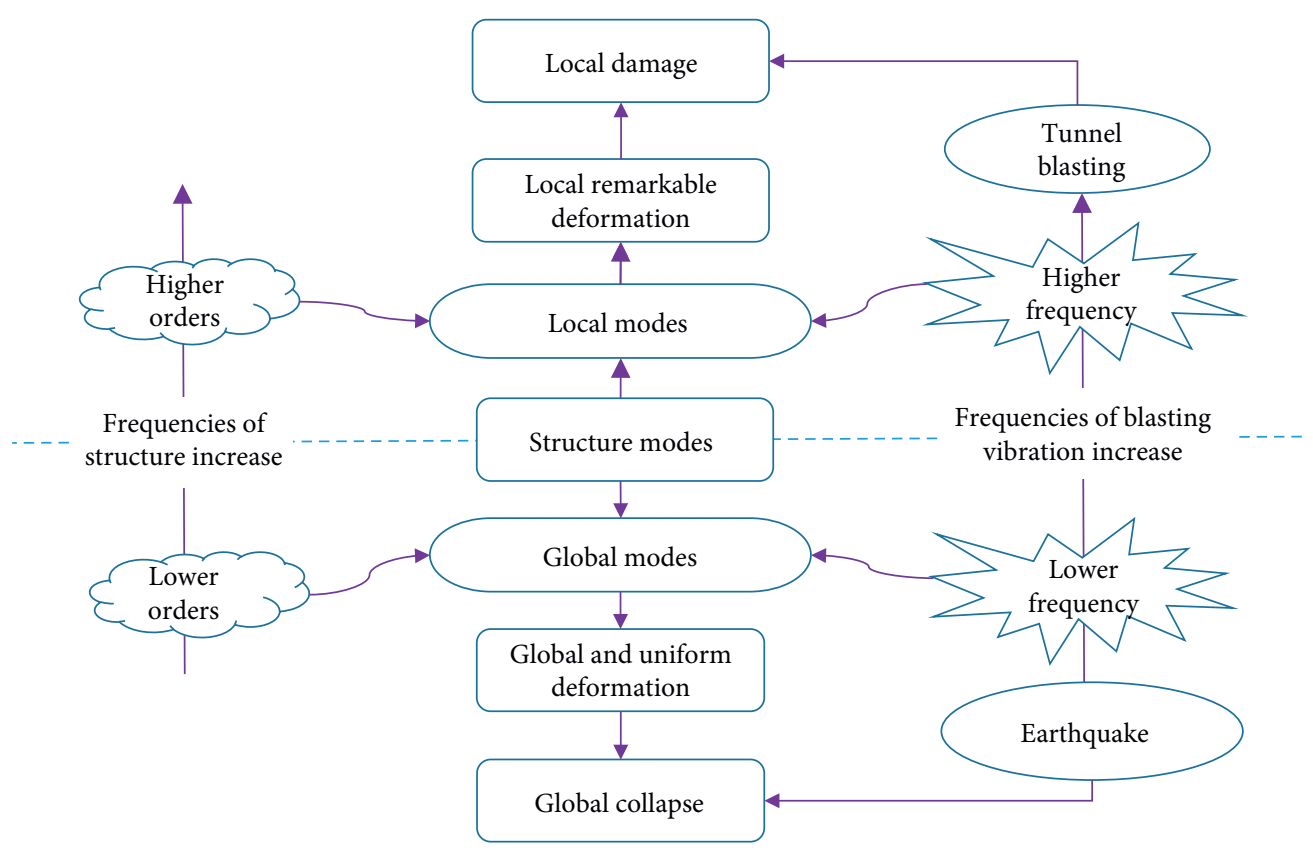

Figure 18: The interaction between external ground motion and structure modes.

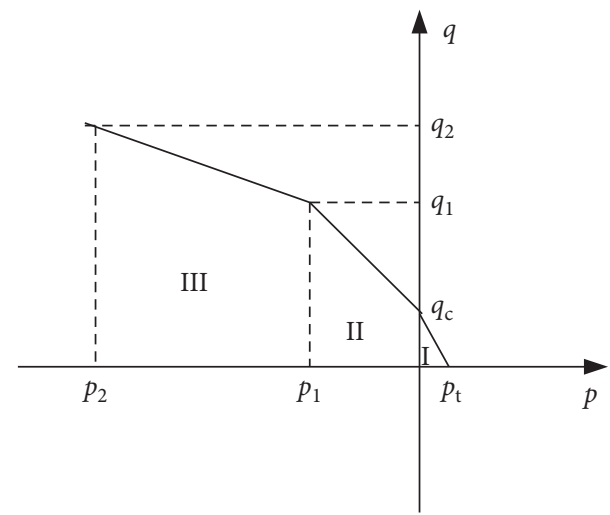

FIGURE 19: Graph showing the strength envelope in the $q-p$ plane and masonry failure modes.

\subsubsection{Principal Compressive Stress (PCS) on Local Members} under High-Frequency Blast Loads. The masonry structure is mainly under pressure subjected to the blasting seismic waves. Firstly, the PCS of the masonry structure caused by blasting seismic waves in $Z$ direction at the peak vibration velocity of $1.0 \mathrm{~cm} / \mathrm{s}$ was analyzed. The PCS contours of the structure are shown in Figures 20 and 21. Then, the PCS values under different peak particle velocities $(1.0 \mathrm{~cm} / \mathrm{s}$, $3.0 \mathrm{~cm} / \mathrm{s}, 6.0 \mathrm{~cm} / \mathrm{s}$ ) are given in Table 7. In Table 7, the PCS ratio is the ratio value of other local members to longitudinal wall (H116939) under different peak particle velocities $(1.0 \mathrm{~cm} / \mathrm{s}, 3.0 \mathrm{~cm} / \mathrm{s}$, and $6.0 \mathrm{~cm} / \mathrm{s})$, respectively, to analyze the different stress responses of different local members. The PCS curve of local members under different peak particle velocities is shown in Figure 22.

From Table 7 and Figure 22, the results are as follows:

(1) Due to the sudden change of stiffness, the stress concentration of floor and wall contact area is caused. As a result, the stress level of the brick wall at the interface is the highest, and the PCS of floor and wall contact area is about 6 times larger than that of the longitudinal wall stress, which is prone to damage. Secondly, due to the obvious stress concentration in the corner, the PCS of the door corner and window corner is about 3 to 5 times larger than that of the longitudinal wall. Next, the PCS of local members of high-order local modes is about 2 to 3 times larger than that of the longitudinal wall because of intensive vibration. The PCS of the longitudinal wall is lowest.

(2) With the vibration velocity increasing, the PCS of members gradually increases. It indicates that the increase of velocity of blasting seismic wave will increase the corresponding dynamic response of the structure, and the peak value of the structural stress will also gradually increase, which will lead to increase the possibility of structural damage or aggravate structural damage.

6.2.3. Principal Tensile Stress (PTS) on Local Members under High-Frequency Blast Loads. The damage of masonry structure is controlled by the maximum principal tensile stress subjected to the blasting seismic waves. Firstly, the PTS of the masonry structure caused by blasting seismic waves in $Z$ direction at the peak vibration velocity of $1.0 \mathrm{~cm} / \mathrm{s}$ was analyzed. The PTS contours of the structure are shown in Figures 23 and 24. Then, the PTS values under different peak particle velocities $(1.0 \mathrm{~cm} / \mathrm{s}, 3.0 \mathrm{~cm} / \mathrm{s}, 6.0 \mathrm{~cm} / \mathrm{s})$ are given in Table 8. In Table 8, the PTS ratio is the ratio value of other local members to longitudinal wall (H116939) under different peak particle velocities $(1.0 \mathrm{~cm} / \mathrm{s}, 3.0 \mathrm{~cm} / \mathrm{s}$, and $6.0 \mathrm{~cm} / \mathrm{s}$ ), respectively, to analyze the different stress responses of different local members. The PTS curve of local 

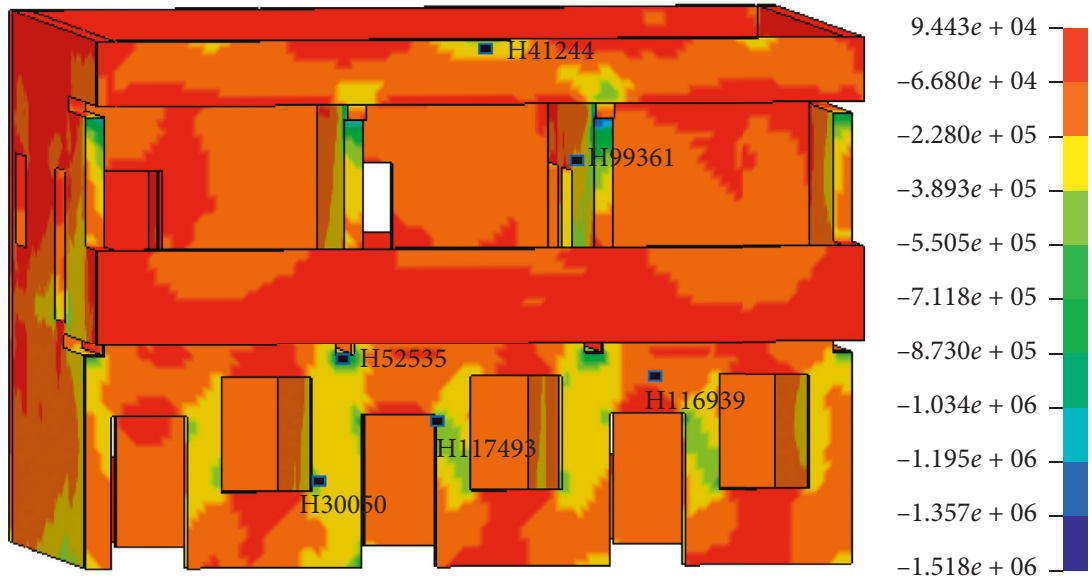

FIGURE 20: PCS contour of the structure $(t=0.058 \mathrm{~s})$ (unit: Pa).
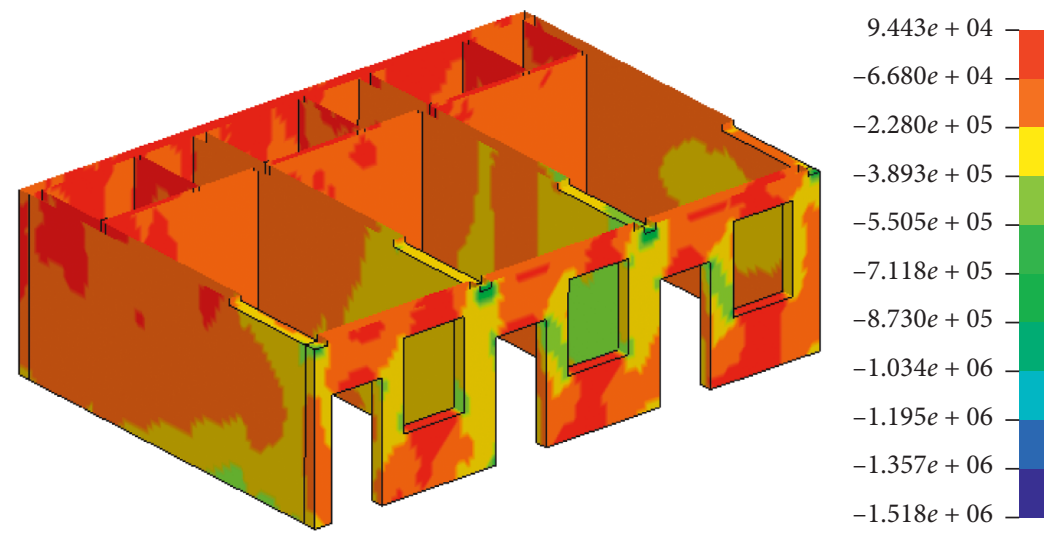

FIgURE 21: PCS contour of first floor section the structure $(t=0.058 \mathrm{~s})$ (unit: Pa).

TABLE 7: PCS and PCS ratio of local members under different peak particle velocities.

\begin{tabular}{|c|c|c|c|c|c|c|c|c|}
\hline Type & Different members & $\begin{array}{l}\text { Typical } \\
\text { elements }\end{array}$ & $\begin{array}{l}\text { Maximum PCS } \\
(\mathrm{MPa}) \\
1.0(\mathrm{~cm} / \mathrm{s})\end{array}$ & $\begin{array}{l}\text { PCS } \\
\text { ratio }\end{array}$ & $\begin{array}{l}\text { Maximum PCS } \\
(\mathrm{MPa}) \\
3.0(\mathrm{~cm} / \mathrm{s})\end{array}$ & $\begin{array}{l}\text { PCS } \\
\text { ratio }\end{array}$ & $\begin{array}{l}\text { Maximum PCS } \\
(\mathrm{MPa}) \\
6.0(\mathrm{~cm} / \mathrm{s})\end{array}$ & $\begin{array}{l}\text { PCS } \\
\text { ratio }\end{array}$ \\
\hline Main structure & Longitudinal wall & H116939 & 0.17 & 1.00 & 0.18 & 1.00 & 0.25 & 1.00 \\
\hline \multirow{2}{*}{ Local members } & Partition wall & H99361 & 0.53 & 3.12 & 0.57 & 3.17 & 0.69 & 2.76 \\
\hline & Front parapet wall & H41244 & 0.40 & 2.35 & 0.49 & 2.72 & 0.68 & 2.72 \\
\hline \multirow{3}{*}{$\begin{array}{l}\text { Stress } \\
\text { concentration } \\
\text { Floor and wall } \\
\text { contact area }\end{array}$} & Window corners & H30050 & 0.61 & 3.59 & 0.67 & 3.72 & 0.84 & 3.36 \\
\hline & Door corners & H117493 & 0.76 & 4.47 & 0.88 & 4.89 & 1.12 & 4.48 \\
\hline & $\begin{array}{l}\text { First floor and wall } \\
\text { contact area }\end{array}$ & H52535 & 0.98 & 5.76 & 1.07 & 5.94 & 1.40 & 5.60 \\
\hline
\end{tabular}

members under different peak particle velocities is shown in Figure 25. The PTS ratio curve of local members under different peak particle velocities is shown in Figure 26.

From Table 8 and Figures 25 and 26, the results are as follows:

(1) The PTS of different local members of the masonry structure appears to vary widely. The PTS of the longitudinal wall is minimized. Due to the stress concentration in local members, such as window corners and door corners, their PTS is maximized. Besides this, the PTS of corners is about 3 to 21 times higher than that of the longitudinal wall. Next, the
PTS of local members in local modes with intensive vibration, such as the balcony, partition wall, and front parapet wall, is approximately 2 to 15 times larger than the longitudinal wall. Finally, the PTS of floor and wall contact area is approximately 4 to 10 times larger than the longitudinal wall.

(2) With the vibration velocity increasing, the PTS of members gradually increases. It shows that the increase of velocity of blasting seismic wave will remarkably enlarge the dynamic response of the structure, which will lead to increase the possibility of structural damage or aggravate structural damage. 


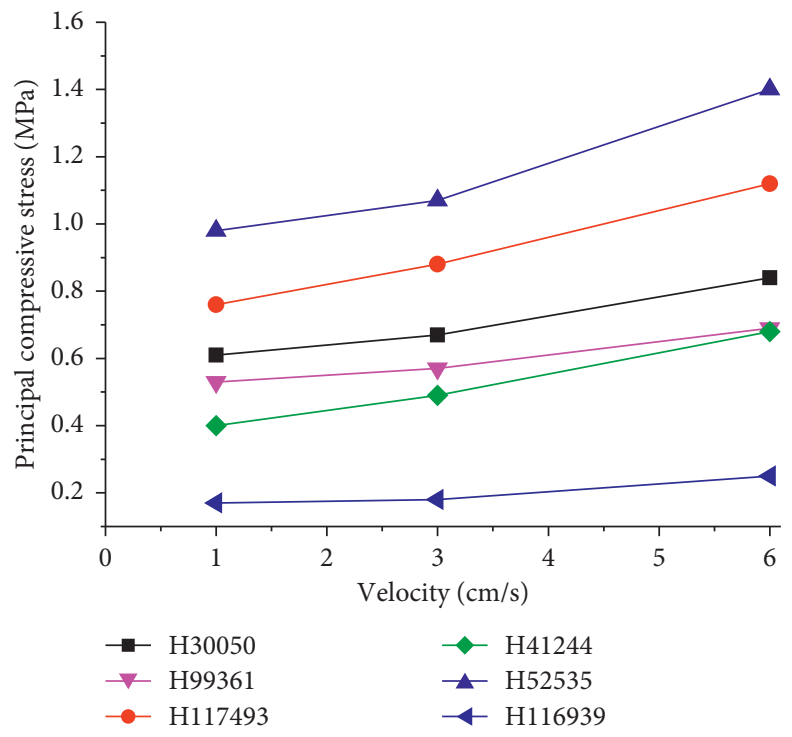

Figure 22: The PCS curve of local members under different peak particle velocities.
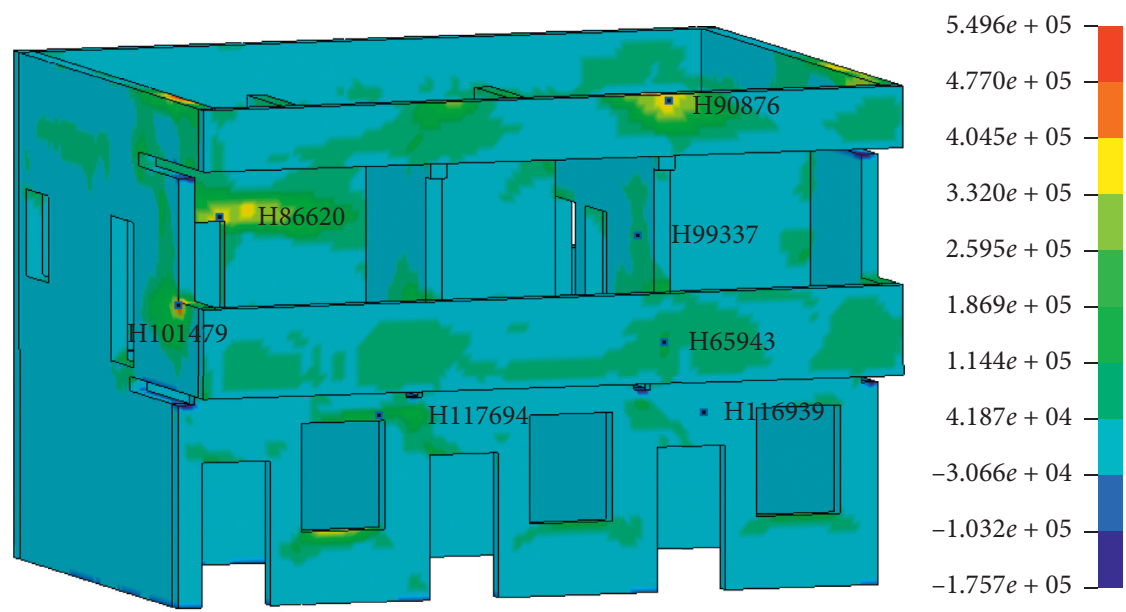

FIGURE 23: PTS contour of the structure $(t=0.101 \mathrm{~s})$ [13] (unit: Pa).
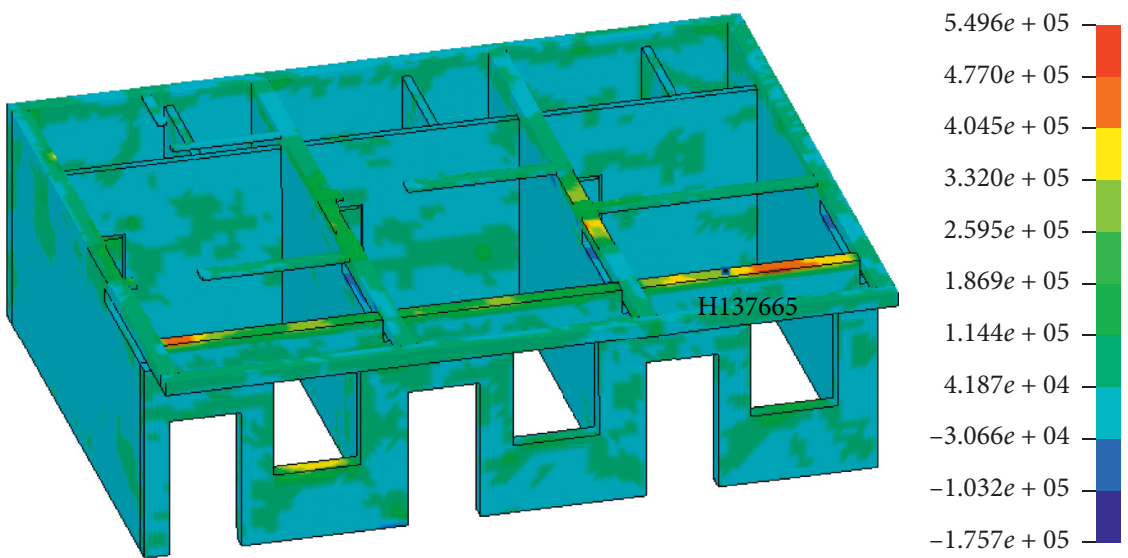

FIGURE 24: PTS contour on the first floor cross section $(t=0.101 \mathrm{~s})$ [13] (unit: Pa). 
TABLE 8: PTS and PTS ratio of local members under different peak particle velocities.

\begin{tabular}{|c|c|c|c|c|c|c|c|c|}
\hline Type & Different members & $\begin{array}{l}\text { Typical } \\
\text { elements }\end{array}$ & $\begin{array}{c}\text { Maximum PTS } \\
(\mathrm{MPa}) \\
1.0(\mathrm{~cm} / \mathrm{s})\end{array}$ & $\begin{array}{l}\text { PTS } \\
\text { ratio }\end{array}$ & $\begin{array}{l}\text { Maximum PTS } \\
(\mathrm{MPa}) \\
3.0(\mathrm{~cm} / \mathrm{s})\end{array}$ & $\begin{array}{l}\text { PTS } \\
\text { ratio }\end{array}$ & $\begin{array}{l}\text { Maximum PTS } \\
(\mathrm{MPa}) \\
6.0(\mathrm{~cm} / \mathrm{s})\end{array}$ & $\begin{array}{l}\text { PTS } \\
\text { ratio }\end{array}$ \\
\hline \multirow[t]{2}{*}{ Main structure } & Longitudinal wall & H116939 & 0.034 & 1.00 & 0.058 & 1.00 & 0.098 & 1.00 \\
\hline & Balcony & H65943 & 0.24 & 7.06 & 0.16 & 2.76 & 0.22 & 2.24 \\
\hline \multirow[t]{3}{*}{ Local members } & Partition wall & H99337 & 0.27 & 7.94 & 0.37 & 6.38 & 0.49 & 5.00 \\
\hline & Front parapet wall & H90876 & 0.51 & 15.00 & 0.60 & 10.34 & 0.70 & 7.14 \\
\hline & Window corners & H117694 & 0.34 & 10.00 & 0.28 & 4.83 & 0.38 & 3.88 \\
\hline \multirow{2}{*}{$\begin{array}{l}\text { Stress } \\
\text { concentration }\end{array}$} & Door corners & H86620 & 0.70 & 20.59 & 0.71 & 12.24 & 0.99 & 10.10 \\
\hline & $\begin{array}{l}\text { Window corners of } \\
\text { side wall }\end{array}$ & H101479 & 0.55 & 16.18 & 0.65 & 11.21 & 0.80 & 8.16 \\
\hline $\begin{array}{l}\text { Floor and wall } \\
\text { contact area }\end{array}$ & $\begin{array}{l}\text { First floor and wall } \\
\text { contact area }\end{array}$ & H137665 & 0.35 & 10.29 & 0.36 & 6.21 & 0.40 & 4.08 \\
\hline
\end{tabular}

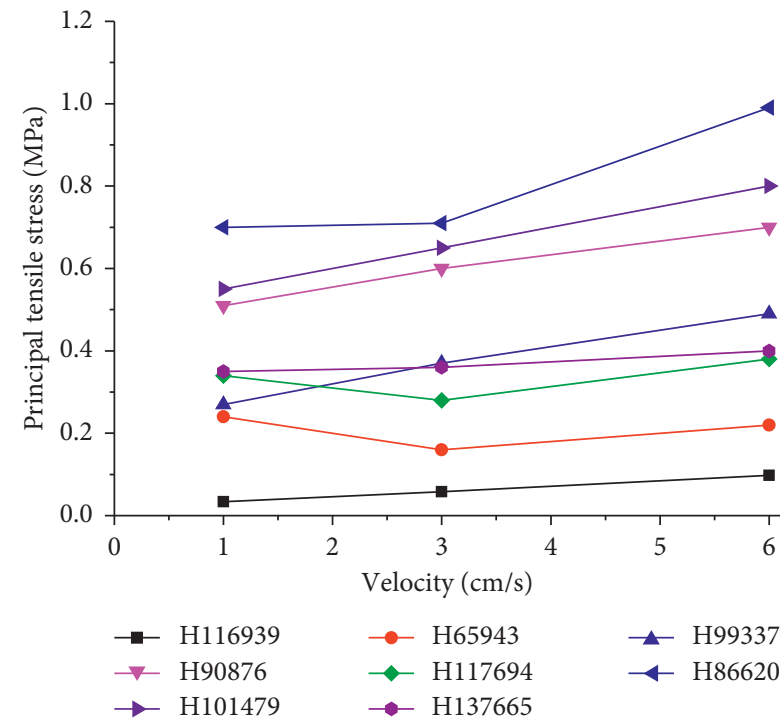

FIgURe 25: The PTS curve of local members under different peak particle velocities.

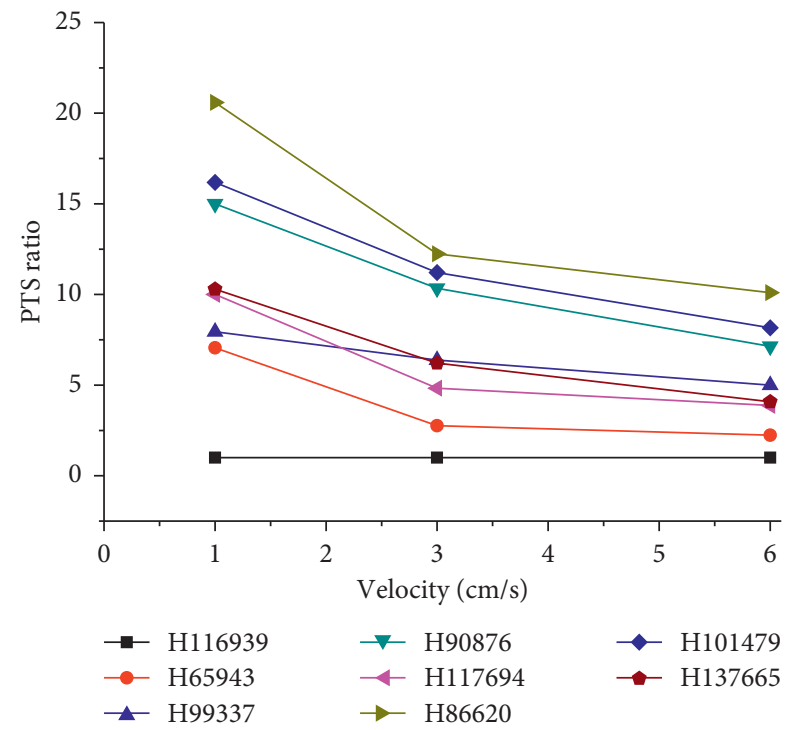

FIgURE 26: The PTS ratio curve of local members under different peak particle velocities.
(3) The PTS ratio of local members decreases with the increase of peak particle velocities. The PTS of the longitudinal wall becomes larger significantly with the increase of peak particle velocities so that the PTS ratio becomes smaller.

6.3. Damage Mechanisms and Locations in the Masonry Structure. The stress response is more significant than the displacement response for a structure under high-frequency ground motion induced by tunnel blasting. The damage is governed by the stress because of the short duration of the blasting vibration. Based on the modal analysis, the frequencies of blasting seismic waves in the near-zone are commonly close to local mode frequencies, which result in intensive vibration in the local members. On the other hand, by analyzing the dynamic responses of the masonry structure under tunnel blasting vibration, the tensile stress of local members is approximately several times larger than the main body structure. When the tensile stress of a local member exceeds the tensile strength of the material, the local member will be damaged and will crack. With regard to the masonry building, masonry is more vulnerable compared to concrete. Since the compressive strength of a brick wall is much larger than the tensile strength, compression failure of the brick walls does not occur while tensile failure of the brick wall is likely to occur. The stress concentration points, such as door corners and window corners, may crack at a relatively low peak velocity. With increasing peak particle velocity, the stress on local members with larger deformation and concrete and brick contact area, such as the parapet, mid-board, and balcony, floor-wall contact area, may exceed the mechanical strength of the material and crack. The main structure of the masonry building is unlikely to record damage due to the relatively low stresses. Damaged locations in the masonry structure found at the site are in accordance with the dynamic response result. The sequence diagram of structural damage is shown in Figure 27 with an increase of the velocity of the vibration.

\section{Conclusion}

Damage assessment and dynamic response of aging masonry structures for blast-induced ground motion are performed 


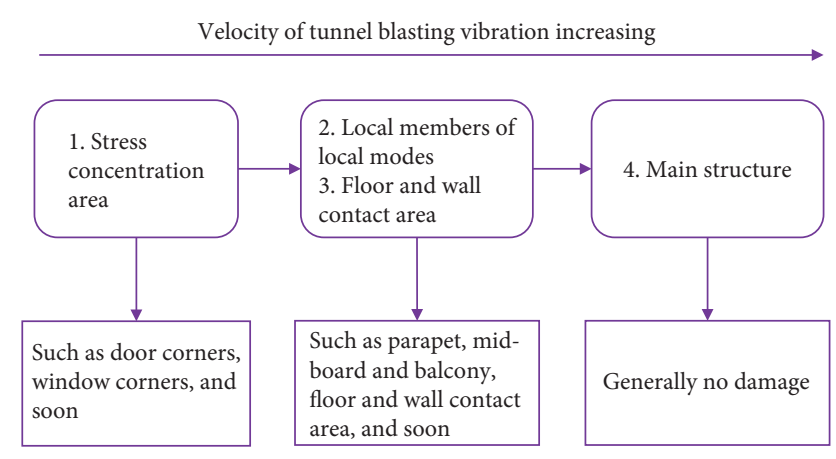

FIgURE 27: The sequence diagram of structural damage.

by using the modal analysis method. Based on the on-site survey and numerical results, the following conclusions can be drawn: (1) in the near shallow tunnel blasting, the blasting seismic waves always have a high frequency, large peak velocity, and short duration time. The damage is common in local members of the structure, consisting of stress concentration points, precast floor joints, and the contact between concrete floors and masonry walls. (2) The first five natural frequencies ranged from 8.80 to $24.99 \mathrm{~Hz}$. The sixth through twentieth natural frequencies ranged from 26.10 to $36.34 \mathrm{~Hz}$, and the deformation of sixth through twentieth was greater than the global deformation. Because the principal frequencies of tunnel blast vibration were closer to the natural frequencies of local members, local members experience more intense vibrations. (3) The principal compressive stress (PCS) and principal tensile stress (PTS) of local members were several times greater than those of the main body structure. Therefore, local members of the masonry building suffered most from the tunnel blasting vibration. With the vibration velocity increasing, the PCS and PTS of local members gradually increase. But, the PTS ratio of local members decreases with the increase of peak particle velocities. The dynamic response analysis result and the damage locations using highorder local modal analysis method are in accordance with the damage found at the site.

\section{Data Availability}

The data used to support the findings of this study are included within the article. All authors confirm that there are no restrictions on sharing of data and/or materials.

\section{Conflicts of Interest}

The authors declare that they have no conflicts of interest.

\section{Acknowledgments}

This work was supported by the National Natural Science Foundation of China (project no. 51708317), first-class discipline project funded by the Education Department of Shandong Province, and China Postdoctoral Science Foundation (2017M612226).

\section{References}

[1] Y. Lu, H. Hao, G. Ma, and Y. Zhou, "Simulation of structural response under high-frequency ground excitation," Earthquake Engineering \& Structural Dynamics, vol. 30, no. 3, pp. 307-325, 2001.

[2] G. Ma, H. Hao, Y. Lu, and Y. Zhou, "Distributed structural damage generated by high-frequency ground motion," Journal of Structural Engineering, vol. 128, no. 3, pp. 390-399, 2002.

[3] H. Hao, G.-W. Ma, and Y. Lu, "Damage assessment of masonry infilled RC frames subjected to blasting induced ground excitations," Engineering Structures, vol. 24, no. 6, pp. 799809, 2002.

[4] G. Ma, H. Hao, and Y. Lu, "Modelling damage potential of high-frequency ground motions," Earthquake Engineering \& Structural Dynamics, vol. 32, no. 10, pp. 1483-1503, 2003.

[5] H. Hao and C. Wu, "Numerical study of characteristics of underground blast induced surface ground motion and their effect on above-ground structures. Part II. Effects on structural responses," Soil Dynamics and Earthquake Engineering, vol. 25, no. 1, pp. 39-53, 2005.

[6] C. Wu, H. Hao, and Y. Lu, "Dynamic response and damage analysis of masonry structures and masonry infilled RC frames to blast ground motion," Engineering Structures, vol. 27, no. 3, pp. 323-333, 2005.

[7] A. Bayraktar, T. Türker, A. Can Altunişik, and B. Sevim, "Evaluation of blast effects on reinforced concrete buildings considering operational modal analysis results," Soil Dynamics and Earthquake Engineering, vol. 30, no. 5, pp. 310$319,2010$.

[8] A. Bayraktar, A. C. Altunişik, and M. Özcan, "Safety assessment of structures for near-field blast-induced ground excitations using operational modal analysis," Soil Dynamics and Earthquake Engineering, vol. 39, pp. 23-36, 2012.

[9] J. W. Yi and Y. Zhou, "Research on physical parameter identification of concrete frame structure on elastic foundation based on higher modes," Journal of Earthquake Engineering and Engineering Vibration, vol. 27, no. 1, pp. 117-124, 2007, (in Chinese).

[10] J. W. Yi, G. L. Wu, and L. Xu, "Research on structural damage diagnosis based on structural high order local modes," Journal of Dynamics and Control, vol. 4, no. 4, pp. 363-369, 2006.

[11] X. M. Guan, Z. W. Yu, J. D. Song, Y. B. Hu, P. Zhang, and Z. S. Hua, "Blasting monitoring and vibration reduction technology of tunnel underpass deep buried water supply pipeline with ultra-small clear distance," China Civil Engineering Journal, vol. 50, no. S2, pp. 160-166, 2017.

[12] X. M. Guan, H. X. Fu, M. S. Wang, C. X. Guo, K. Liu, and T. L. Liu, "Local dynamic response of a masonry structure to the vibrations of tunnel blasting," Modern Tunnelling Technology, vol. 54, no. 3, pp. 135-141, 2017.

[13] X. M. Guan, C. W. Zhang, P. Zhang, X. C. Wang, and Z. N. Yang, "Stress response and damage of a masonry structure subjected to ground motion induced by tunnel blasting using modal analysis method," in Proceedings of the 24th Australasian Conference on the Mechanics of Structures and Materials, Perth, Australia, pp. 747-753, December 2016.

[14] B. F. Sun, H. X. Fu, X. M. Guan, and M. S. Wang, "Decreasing vibration technology for tunnel blasting based on building modal analysis," China Journal of Highway and Transport, vol. 29, no. 10, pp. 86-94, 2016.

[15] D. Q. Kong, X. M. Guan, and H. X. Fu, "Dynamic response characteristics analysis of a two-story masonry structure to 
tunnel vertical blast ground motion," China Civil Engineering Journal, vol. 48, no. S1, pp. 326-330, 2015.

[16] X. M. Guan, H. X. Fu, M. S. Wang, K. P. Cui, and F. T. Lin, "Finite element modeling and model updating of brick masonry structure based on modal parameters obtained from operational modal analysis," Journal of Vibration and Shock, vol. 33, no. 14, pp. 181-187, 2014.

[17] X. M. Guan, H. X. Fu, and M. S. Wang, "Blasting vibration characteristics monitoring of tunnel under-passing hillside buildings in short-distance," Rock and Soil Mechanics, vol. 35, no. 7, pp. 1995-2003, 2014.

[18] R. Cantieni, "Experimental methods used in system identification of civil engineering structures," in Proceedings of the 2th Workshop: Problemi di Vibrazioni Nelle Strutture Civili e Nelle Costruzioni Meccaniche, pp. 10-11, Perugia, Italy, June 2004.

[19] G. D. Roeck, B. Peeters, and W. X. Ren, "Benchmark study on system identification through ambient vibration measurements," in Proceedings of the 18th International Modal Analysis Conference, pp. 1106-1112, San Antonio, TX, USA, February 2000.

[20] B. Jaishi and W.-X. Ren, "Structural finite element model updating using ambient vibration test results," Journal of Structural Engineering, vol. 131, no. 4, pp. 617-628, 2005.

[21] S. V. Modak, T. K. Kundra, and B. C. Nakra, "Comparative study of model updating methods using simulated experimental data," Computers \& Structures, vol. 80, no. 5-6, pp. 437-447, 2002.

[22] C. E. Ventura and K. M. Thibert, "Dynamic properties of a 32storey building determined from different analysis methods of ambient vibration test data," in Proceedings of the Second International Operational Modal Analysis Conference, pp. 557-564, Copenhagen, Denmark, April 2007.

[23] D. Zonta, A. Elgamal, M. Fraser, and M. J. Nigel Priestley, "Analysis of change in dynamic properties of a frame-resistant test building," Engineering Structures, vol. 30, no. 1, pp. 183-196, 2008.

[24] J. F. Lord, C. E. Ventura, and E. Dascotte, “Automated model updating using ambient vibration data from a 48-storey building in Vancouver," in Proceedings of the 22nd International Modal Analysis Conference, pp. 26-29, Dearborn, MI, USA, January 2004.

[25] J. R. Wu and Q. S. Li, "Finite element model updating for a high-rise structure based on ambient vibration measurements," Engineering Structures, vol. 26, no. 7, pp. 979-990, 2004.

[26] X. M. Guan, "Dynamic response and control technology of masonry structure under tunnel blasting," Doctor thesis, Beijing Jiaotong University, Beijing, China, 2015.

[27] R. W. Clough and P. Joseph, Dynamics of Structures, McGraw-Hill, New York, NY, USA, 2nd edition, 1993. 


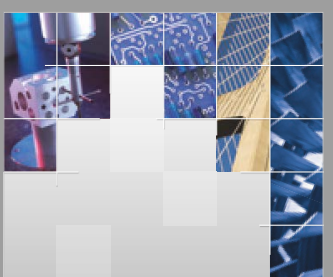

\section{Enfincering}
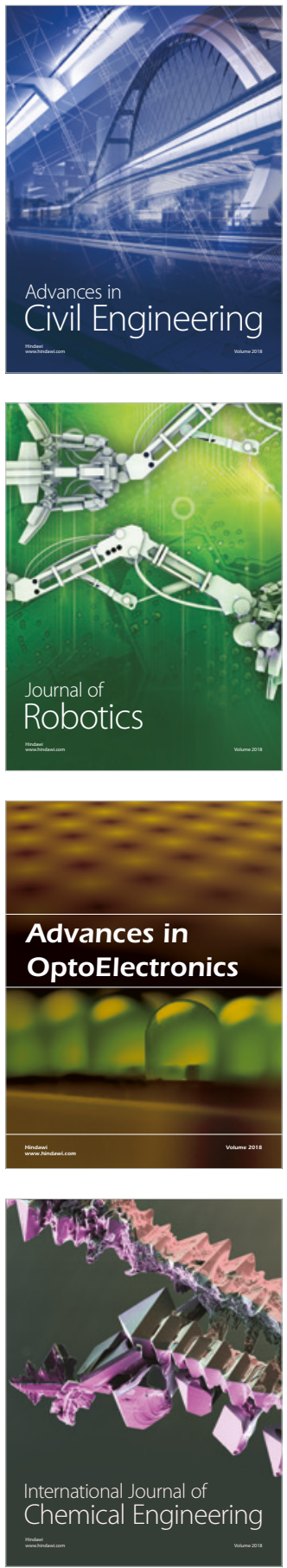

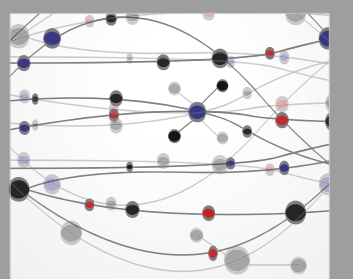

\section{Rotating \\ Machinery}

The Scientific World Journal

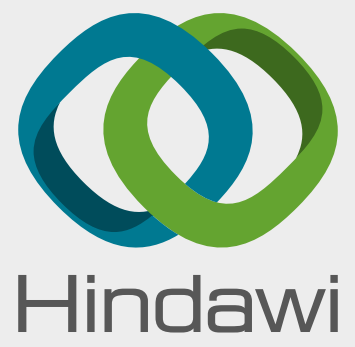

Submit your manuscripts at

www.hindawi.com
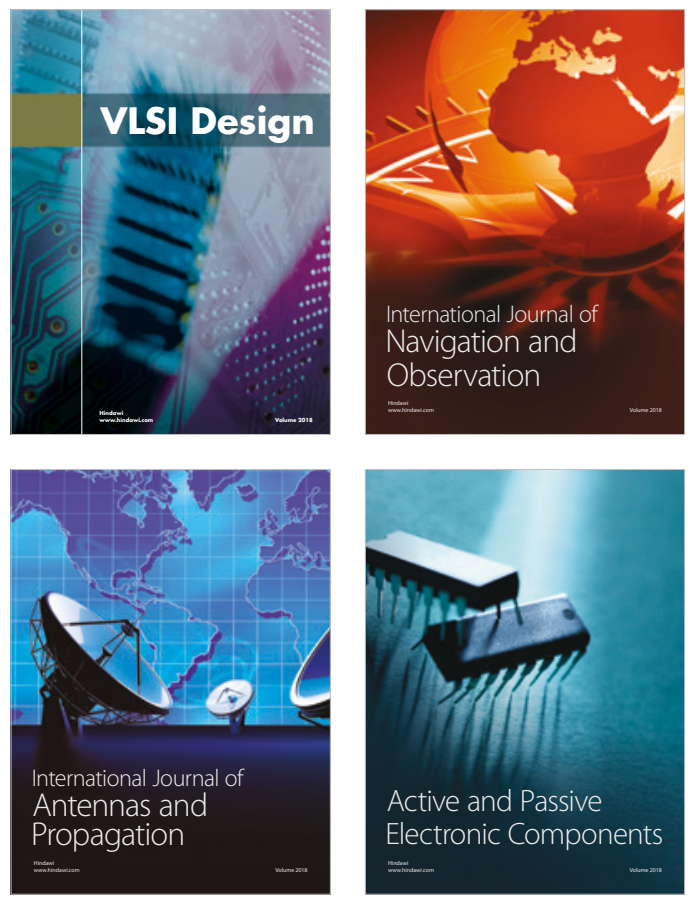
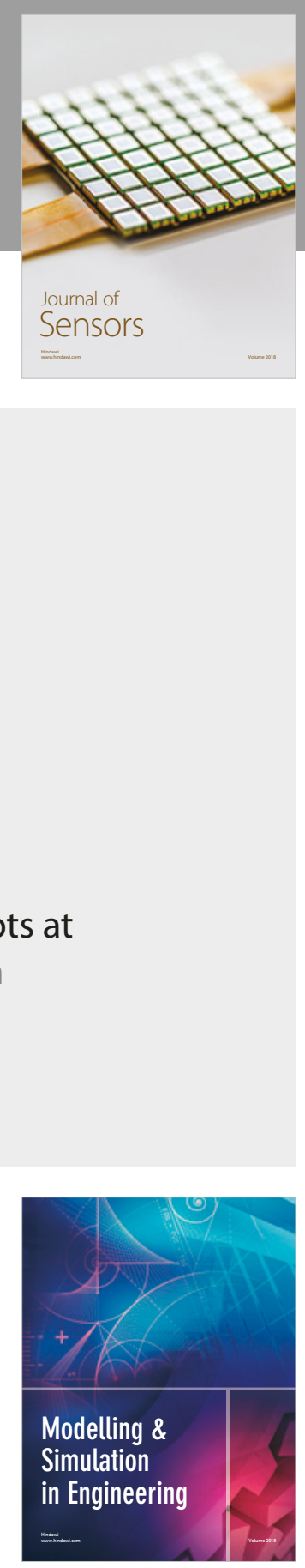

\section{Advances \\ Multimedia}
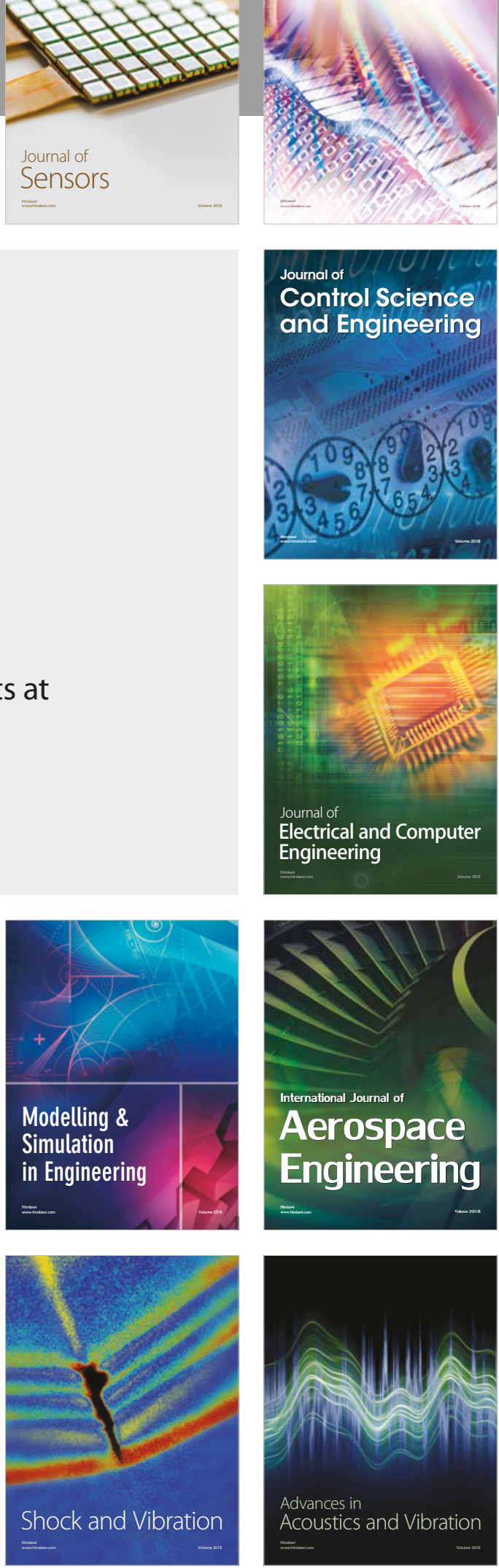